\title{
Honeywell
}

\section{Development of a Fiber Laser Welding Capability for a Firing Set}

Federal Manufacturing \& Technologies

Jose A. Samayoa

KCP-613-8748

Published April 2010

Final Report

Approved for public release; distribution is unlimited.

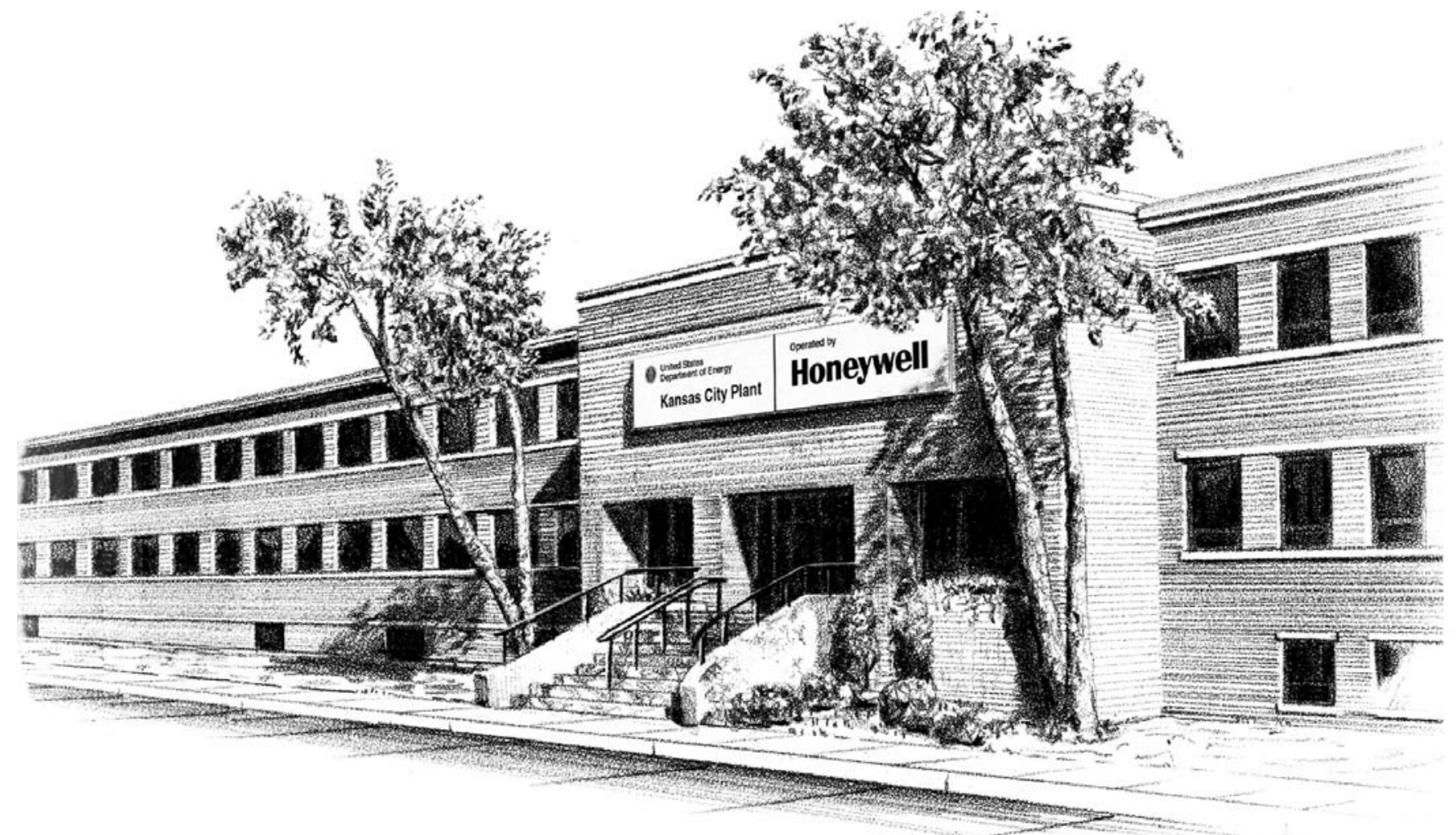

Prepared under prime contract DE-ACO4-01AL66850 for the United States Department of Energy 


\section{DISCLAIMER}

This report was prepared as an account of work sponsored by an agency of the United States Government. Neither the United States Government nor any agency thereof, nor any of their employees, makes any warranty, express or implied, or assumes any legal liability or responsibility for the accuracy, completeness, or usefulness of any information, apparatus, product, or process disclosed, or represents that its use would not infringe privately owned rights. Reference herein to any specific commercial product, process or service by trade names, trademark, manufacturer, or otherwise, does not necessarily constitute or imply its endorsement, recommendation or favoring by the United States Government or any agency thereof. The views and opinions of authors expressed herein do not necessarily state or reflect those of the United States Government or any agency thereof.

All data prepared, analyzed and presented has been developed in a specific context of work and was prepared for internal evaluation and use pursuant to that work authorized under the reference contract. Reference herein to any specific commercial product, process or service by trade name, trademark, manufacturer, or otherwise, does not necessarily constitute or imply its endorsement, recommendation or favoring by the United States Government, any agency thereof or Honeywell Federal Manufacturing \& Technologies, LLC.

Printed in the United States of America.

This report has been reproduced from the best available copy.

Available to DOE and DOE contractors from the Office of Scientific and Technical Information, P.O. Box 62, Oak Ridge, Tennessee 37831; prices available from (865) 576-8401, FTS 626-8401.

Available to the public from the National Technical Information Service, U.S. Department of Commerce, 5285 Port Royal, Rd., Springfield, Virginia 22161, (703) 487-4650.

A prime contractor with the United States Department of Energy under Contract Number DE-AC04-O1AL66850

\author{
Honeywell Federal Manufacturing \& Technologies \\ P.O. Box 419159 \\ Kansas City, Missouri, 64141-6159
}




\section{Honeywell}

KCP-613-8748

Distribution Category UC-42

Approved for public release; distribution is unlimited.

Development of a Fiber Laser Welding Capability

for a Firing Set

Jose A. Samayoa

Published April 2010

Final Report

Brad Pearce, Project Leader

Project Team:

Scott Murawski

Tim Ward 


\section{Contents}

Section Page

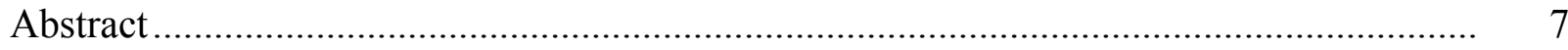

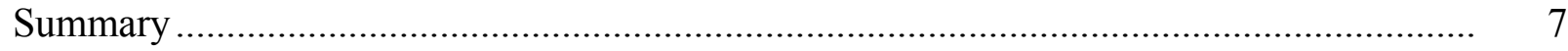

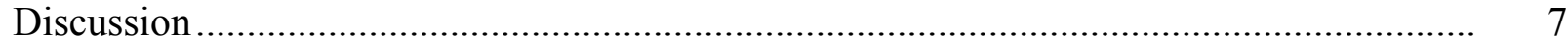

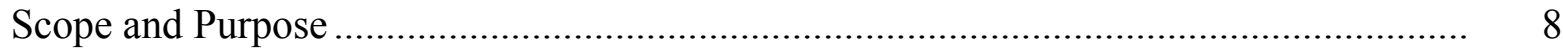

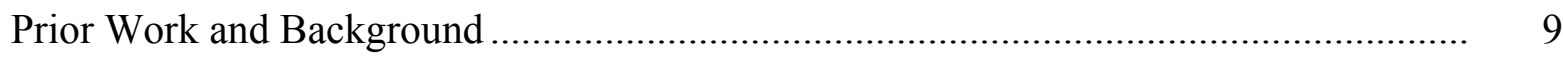

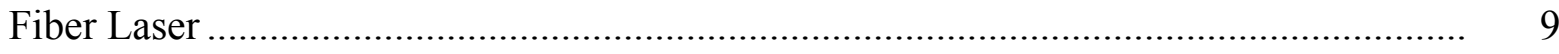

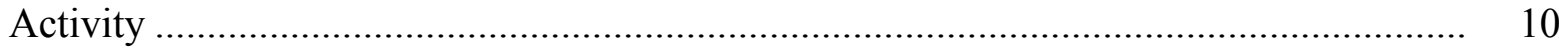

Standard Deviation Comparison ............................................................... 11

Porosity Performance by Lens Focal Lengths ............................................. 11

Focus Characterization........................................................................... 12

Welding Experimentation ................................................................. 13

Process Capability Charts for Butted Seams and S/Ps................................ 17

TSL Qualification Welds ......................................................................... 18

Process Capability of Reset Ring Fillets...................................................... 20

Ground Strap and Flatness Cover Weld Parameter Selection .......................... 21

Secondary Attachment Pins Parameter Selection .......................................... 23

Process Capability of Secondary Attachment Pins ........................................ 25

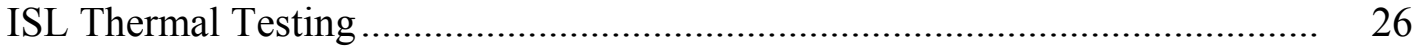

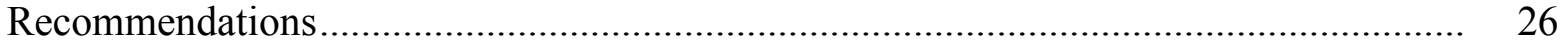

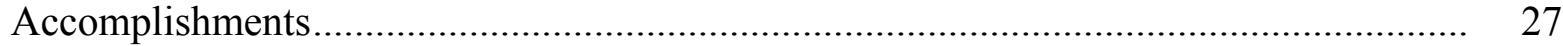

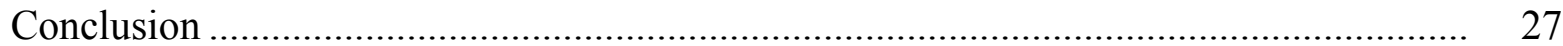

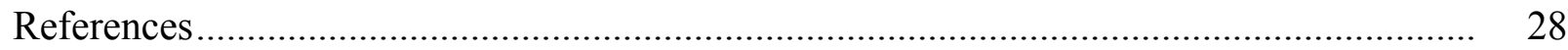

Appendices.

A. Fiber Laser Qualification Results ............................................................ 29

B. WPQR Settings for Validation.................................................................... 31

C. Weld Metallography ................................................................................. 33 


\section{Illustrations}

Figures Page

1 Distribution of Weld Penetration Values from Weld Wualifications and Resulting Standard Deviation Numbers for Each Group ................................................. 11

2 Porosity Performance by Focal Length................................................................ 12

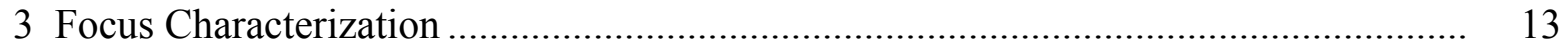

4 Power Output by Output \% Setting Showing Excellent Linearity ............................ 14

5 Output Power \% by Weld Penetration, S/Ps.......................................................... 15

6 \% Power by Weld Width, S/Ps............................................................................. 15

7 Extended Penetration Testing by Power in Watts, S/Ps, Showing a PI...................... 16

8 Non-TSL Seam Welds Process Capability ............................................................ 17

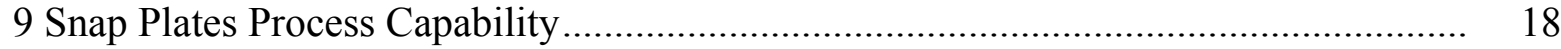

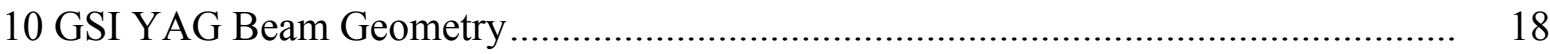

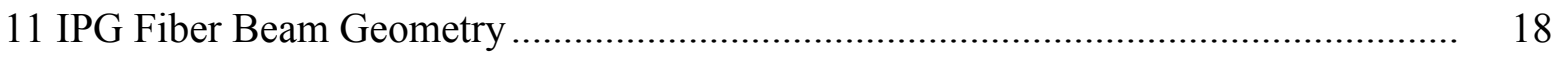

12 TSL Penetration for Various Power \% as Measured on a Simulated Part. ................ 19

13 TSL Penetration and Width from Simulated TSL Part with Segmented Welds .......... 20

14 TSL Process Capability of Qualification Welds................................................... 20

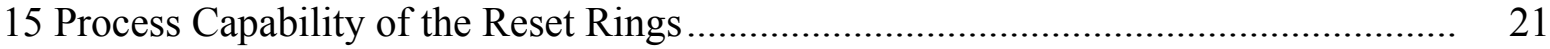

16 Ground Strap and Flatness Covers Penetration by \% and Pulse Duration ................. 22

17 Ground Strap and Flatness Covers Spot Diameter by \% and Pulse Duration ............. 22

18 Placement of Spot Welds on Secondary Attachment Pins ...................................... 25

19 Process Capability of Secondary Attachments Pins ….......................................... 26

20 Orientation of Thermocouples and Weld Direction from "Home" .......................... 26

\section{Tables}

Number

Table

1 Pro/Con YAG-to-Fiber Decision Matrix ................................................................... 10

2 DOE Matrix with Range of Parameters Used and Captured

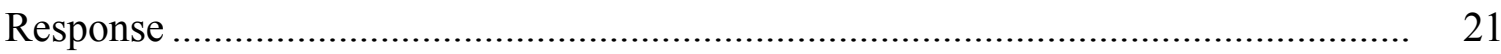

3 Fiber Laser Process Capability and Expected Performance ................................... 23

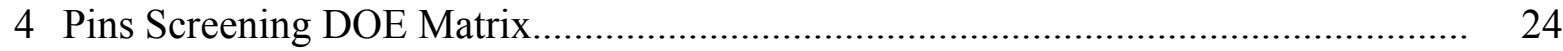

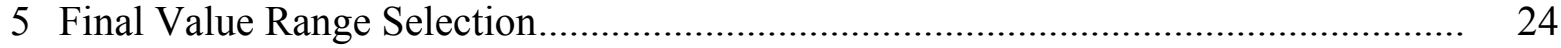




\begin{abstract}
Development work to implement a new welding system for a Firing Set is presented. The new system is significant because it represents the first use of fiber laser welding technology at the KCP. The work used Six-Sigma tools for weld characterization and to define process performance. Determinations of workable weld parameters and comparison to existing equipment were completed. Replication of existing waveforms was done utilizing an Arbitrary Pulse Generator (APG), which was used to modulate the fiber laser's exclusive continuous wave $(C W)$ output. Fiber laser weld process capability for a Firing Set is demonstrated.
\end{abstract}

\title{
Summary
}

Weld characterization and implementation of a new fiber laser welding system was completed in support of Firing Set welding. This work was undertaken to supplement and backup two existing lasers in two departments. Workload studies provided justification for purchasing the extra machine to support production volume and to mitigate schedule risk for the project

The new capacity / backup laser is significant because it represents first-time use of fiber laser technology at the KCP. Fiber lasers are the state-of-the-art in the field of laser equipment. The system procured for the Firing Sets and AF\&F is a CW, $2 \mathrm{KW}$ laser by IPG Photonics of Oxford, MA. Since the fiber laser operates exclusively in the $\mathrm{CW}$ mode, it was equipped with advanced pulsing technology to permit replication of existing sinusoidal and square waveforms matching those of the existing GSI, JK802 $\mathrm{Nd}$ :YAG lasers. Using the device, the new fiber laser was capable of matching the waveform outputs used for production.

The behaviors of weld penetration, weld width, "throat" and rewelds are shown for the new fiber laser. Weld groups per SS1A4542 were welded to cover qualification requirements for the 1A1099 assembly. These also satisfied most of the 1A1900 welds.

For this work, variables were minimized. Weld speed was held constant to existing levels, 70 and 80 IPM. Power levels were initially varied to characterize the range of usable parameters to achieve a target of around $0.027-0.028$ inch weld penetration for butt joints excluding the TSL, which was targeted at 0.022 " nominal. The statistical response for welds tested is presented with predicted process capabilities, which are shown to be compliant at a minimum $4.56 \sigma$ levels from nominal. Thermal testing of the ISL weld was done for comparative purposes indicating comparable temperatures that averaged $183.7^{\circ} \mathrm{C}$ for the Fiber vs. $208^{\circ} \mathrm{C}$ for the existing YAGs. Visual results for the welds were shown to be acceptable. Metallography of the welds studied is presented for applicable weld groups in accordance with SS1A4542. Focus characterization is presented.

\section{Discussion}

This work was required to provide production welding parameters and implement a newly acquired fiber Laser system. An earlier capability of two lasers had been commissioned in 2006 and 2007; however, work load studies indicated the need for further production capacity. Justification for a new third laser was based on this need. 
Selection of the fiber Laser was motivated by the desire for greater reliability and simplicity. The previous CW Nd:YAG lasers had been maintenance-intensive. In contrast, the fiber laser offered increased efficiency, simplicity of design via elimination of hard cavity optics resulting in lower maintenance and, reportedly, improvements in process. A new equipment integrator, Innovative Laser Technologies (ILT) of Minneapolis, MN, was utilized. Familiarity with this contractor's motion software facilitated the programming work. Translation of programs across systems was delegated to the vendor to expedite the process. Most individual geometries and base-line programs from the existing laser welders were converted for use with the fiber equipment.

Much research into fiber Laser technology was done prior to this procurement including visits to manufacturers and completion of welding trials at vendors' sites. A PDRD research project ${ }^{1}$ was completed to investigate the viability of the technology for use at the KCP. Trips were made to fiber laser users, integrators and manufacturers. Medtronics Corporation demonstrated applications of the technology in manufacturing. The Edison Welding Institute demonstrated a system at their facility and was commissioned to perform weld evaluations. Other weld trials were done at IPG Photonics, Alabama Laser and Innovative Laser Technologies (ILT) in Minneapolis. Summaries of these visits are included in the "References" section of this report.

\section{Scope and Purpose}

The work scope included the completion of qualification welds and their evaluation to satisfy weld requirements for production in accordance with SS1A4542, Welding Requirements, MC4702 ${ }^{9}$. The work required characterization of a new fiber laser and development of specific weld parameters to satisfy the stated criteria. Certification of samples involved the production of welds for up to seven unique groups using the new parameters. The welds had to comply with visual criteria and strict penetration and porosity limits as verified by metallography. Compliance to criteria and statistical analyses of process capability were completed. Visual inspection of welds was completed by inspection. Operators were qualified and a third alternate tool, FW414282-403, was fabricated.

To expedite and facilitate the work, the concept of group qualification was used. The concept, defined under weld specification SS1A4542, allows combining like-joint configurations, precluding qualification by individual weld type. This method reduced labor and hardware cost by about $60 \%$ and allowed completion of the work within a compressed time frame. 
Micrographs of over 50 metallurgical sections from welds made on WR housings were taken and over 140 Snap Plates $(\mathrm{S} / \mathrm{P})$ penetration measurements were completed. To optimize use of available hardware, dissimilar parts from equivalent groups, as allowed by the weld specification, were welded to fulfill the quantity requirements. Completed qualification welds were visually inspected and accepted.

Completion of this weld development report and a Welding Procedure Qualification Record (WPQR), listing machine parameters for developed welds, are also required by SS1A4542. This report contains both the WPQR and the development data in combined form. As required, conclusion and issuance of this report, contingent on DA approval, qualifies the fiber laser, CE214603, for production welding of the Firing Set.

\section{Prior Work and Background}

With the primary welding laser (CE212289) being at full capacity during 2006, an additional machine (CE213393) was planned and implemented during 2007 in an annexed location. This new laser (CE213393) was bought in 2005 and duplicated the department's primary welding system. Newer laser systems were technically updated with new MKII power supplies, improved controls, better viewing optics and a faster shutter. The shutter was capable of $0.020 \mathrm{sec}$ cycle times compared to $0.150 \mathrm{sec}$ previously. The new optics system incorporated additional capability to interrupt motion if impact occurred within the three-dimensional work space.

Two reports ${ }^{11,12}$ were published covering the implementations of CE212289 and CE213393. The reports are available as "Green Backs" and listed in the "TRIM" data base of the KCP.

\section{Fiber Laser}

The decision to purchase a fiber laser hinged on the desire for better reliability, repeatability and lower maintenance. Alignment issues are often a factor with lasers that utilize hard optics. One appeal of the fiber laser is the lack of internal optics, which negates alignment issues in their entirety. No hard optics exist internal to the resonator and amplifier.

The fiber laser also has superior beam quality and lower divergence due to the "rifling" effect of the beam-generating amplifier-and-resonator portion of the fiber length. Because it can be up to 20 meters long, it helps collimating the beam.

A comparative decision matrix, Table 1, was created to weigh the characteristics of the YAG and fiber systems. Price and availability issues further influenced the decision towards procurement of a fiber system. The IPG Photonics brand was chosen because of its ability to generate high power, a characteristic unique to this manufacturer and proprietary in the industry.

This fiber laser system is also equipped with switchable beam deliveries, one of which passes the beam through a ScanLab head. The ScanLab head is a galvanometer system rated at maximum output and capable of high-speed marking and welding by rastering the beam without moving the work. 


\begin{tabular}{|c|c|c|c|c|}
\hline \multirow[b]{2}{*}{ Category } & \multicolumn{2}{|l|}{ |CW:YAG } & \multicolumn{2}{|l|}{ |FIBER } \\
\hline & PLUS & MINUS & PLUS & MINUS \\
\hline $\begin{array}{l}\text { Processing } \\
\text { General }\end{array}$ & $\begin{array}{l}\text { 1. Has processing precedent, } \\
\text { established weld development, } \\
\text { parameters, documentation, } \\
\text { programs. } \\
\text { 2. Quickest on-line } \\
\text { implementation, lower } \\
\text { engineering labor due to pre- } \\
\text { exiting process } \\
\text { 3. Good, known welding } \\
\text { characteristics suitable to } \\
\text { product. }\end{array}$ & $\begin{array}{l}\text { 1. Reported power fluctuation } \\
\text { issues. } \\
\text { 2. Updated JK802SM design } \\
\text { uses DC vs. AC supply, } \\
\text { identical cavity design but no } \\
\text { field history - reportedly same } \\
\text { process capability. }\end{array}$ & $\begin{array}{l}\text { 1. KCP weld testing indicates } \\
\text { potentially capable system. } \\
\text { 2. Newest state-of-the-art } \\
\text { technology, highly touted as } \\
\text { desirable by welding } \\
\text { community. }\end{array}$ & $\begin{array}{l}\text { 1. Requires more development. } \\
\text { 2. Highest engineering labor/material } \\
\text { costs, additional sample hardware. } \\
\text { 3. Longest to "on-line" } \\
\text { implementation due to more } \\
\text { development, parameter selection, } \\
\text { report writing, DA buy-in. } \\
\text { DA is favorable to Fiber technology. }\end{array}$ \\
\hline $\begin{array}{l}\text { Process } \\
\text { Capability }\end{array}$ & $\begin{array}{l}\text { 1. YAG has established } \\
\text { process capability. }\end{array}$ & $\begin{array}{l}\text { 1. Output power performance } \\
\text { requires re-tuning procedure to } \\
\text { "re-center" the process. }\end{array}$ & $\begin{array}{l}\text { 1. Linear power response with } \\
\mathrm{R}^{2} \text { of near } 1 .\end{array}$ & \\
\hline $\begin{array}{l}\text { Laser } \\
\text { Capability } 2\end{array}$ & & & $\begin{array}{l}\text { 1. For a given spot size, fiber } \\
\text { laser has approx. } 2 \text { - } 3 X \text { the } \\
\text { focal length and depth of field, } \\
\text { thereby improving focus } \\
\text { insensitivity. }\end{array}$ & \\
\hline Facility & & Largest foot print, largest chiller & $\begin{array}{l}\text { 1. Smallest foot print, smallest } \\
\text { chiller } \\
\text { 2. Most portable }\end{array}$ & \\
\hline$\overline{\text { Cost }}$ & & $\begin{array}{l}\text { Most Expensive- } \\
\text { ILT: } \$ 647,836 \\
\text { Alabama: } \$ 1,035,000 \\
\text { Unitek: } \$ 1,395,250 \\
\text { (funded for } \$ 850,000 \text { ) }\end{array}$ & $\begin{array}{l}\text { Cheapest- } \\
\text { ILT: } \$ 562,846 \\
\text { Alabama: } \$ 930,000 \\
\text { Unitek: } \$ 1,515,500 \\
\text { (funded for } \$ 850,000 \text { ) }\end{array}$ & \\
\hline
\end{tabular}

Table 1. Pro / Con YAG-to-Fiber Decision Matrix

\section{Activity}

As a precursor to this development, a weld penetration baseline of $0.027-0.028$ inch was targeted for the non-TSL seams. This selection was based on previous experience and the production success achieved with the Nd:YAGs, which use penetration plus-biasing in their operation.

The CE212289 development activity had produced a nominal penetration of around 0.0257 , which was central to the tolerance band, and a standard deviation of 0.0027 inch. The second system, CE213393, produced slightly improved nominal penetration of $0.0262 \mathrm{inch}$ and a standard deviation of $0.0021 \mathrm{inch}$.

In order to increase the process margin for the /S/ Lower Specification Limit (LSL), "plus-biasing" of the weld penetration was gradually introduced for both current YAG systems, considering that no resulting degradation to the product was evident. Given this approach, the current operating range is set to $0.026-$ 0.029 inches, or $0.002-0.004$ inches above the specification range nominal. 
The same operating range was adopted for the Fiber system excepting the TSL, which has a lower penetration requirement of $.010-.030 \mathrm{inch}$. For this application a penetration of $0.022 \mathrm{inch}$ was targeted, $10 \%$ above nominal.

The uncentered performance not only enhances process capability for the lower side of the specification, but also reinforces insensitivity to weld fit up and process variation.

\section{Standard Deviation Comparison}

Figure 1, captures the progression of penetration ranges and resulting standard deviations for qualification seam welds by laser CE\#s between CY2006 and CY2010. A distinctive trend is noted that indicates improvements in the standard deviation numbers going across machines from the YAGs to the latest Fiber equipment, which displays the least variation.

Scatterplot, Pen Range and Std Dev. by CE\#

(CE212289, D77, Sept 2006, CE213393, D60, Dec 2007, CE214603, D77 Fiber, Feb 2010)

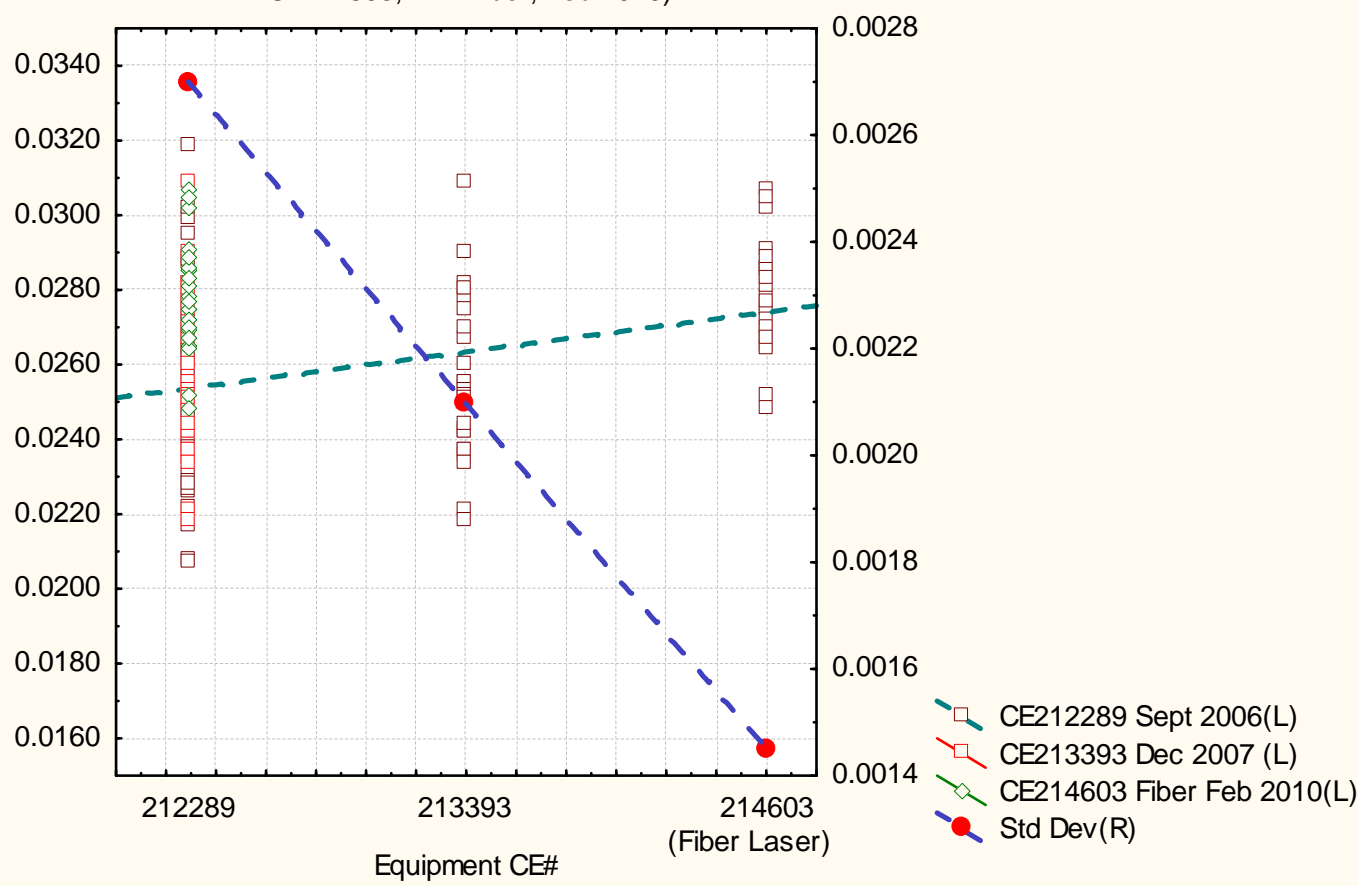

Figure 1. Distribution of Weld Penetration Values from Weld Qualifications and Resulting Standard Deviation Numbers for Each Group

\section{Porosity Performance by Lens Focal Lengths}

Lenses including 120, 160 and $250 \mathrm{~mm}$ were tested. Prior to equipment arrival at the KCP, bead-on-plate (B-o-P) weld trials specific to the 120 and $160 \mathrm{~mm}$ were completed at ILT's facility in Minneapolis. Pore measurements internal to the B-o-P sections indicated that porosity decreased with higher modulation frequency and longer focal lengths ${ }^{8}$. Encouraged by the results, testing was extended to the $250 \mathrm{~mm}$, expecting an even better weldability. Concerns over poor coupling with the longer lens did not materialize. The $250 \mathrm{~mm}$ lens produced the least spatter, optimum weld appearance and superior work clearance. Going forward, the $250 \mathrm{~mm}$ lens was selected for the development work and welding of qualification parts. 
Sections made with this lens exhibited minimal to no porosity and produced the widest weld from the largest focused spot diameter of 312.5 microns. In comparison, the other lenses have spot diameters of 150 and 200 microns, respectively. Large focused spots influence weld width enhancing insensitivity to weld gaps and other fit-up issues. The YAGs $120 \mathrm{~mm}$ lenses have a comparative spot size of 240 microns.Figure 2 shows porosity response at $48 \%$ and $300 \mathrm{~Hz}$.

\section{Box Plot (Porosity by Lens/Modulation Setting for Fiber - BOP)}

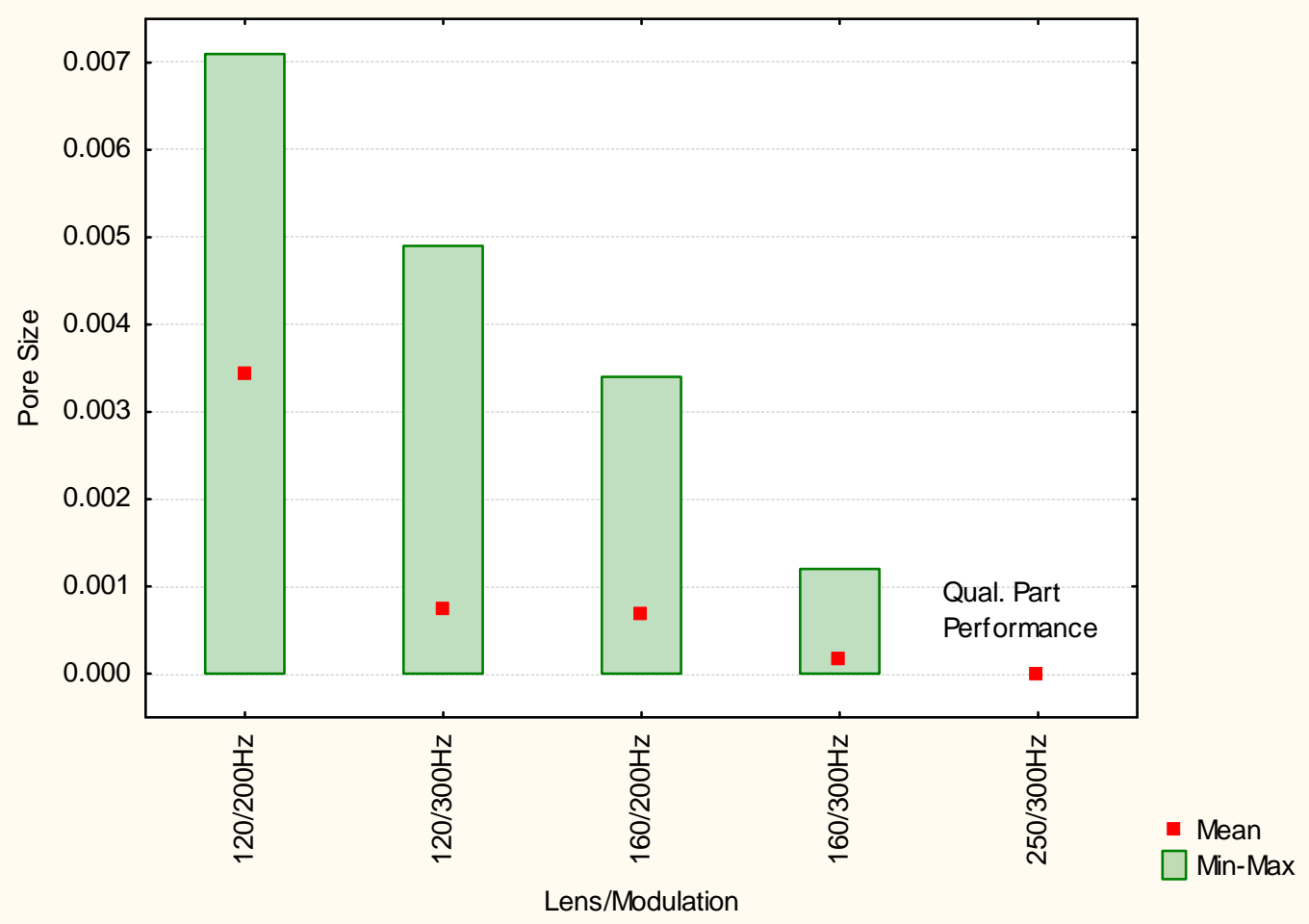

Figure 2. Porosity Performance by Focal Length

\section{Focus Characterization}

Focus characterization was completed prior to the startup of qualification welding.

To characterize true focus position for the selected $250 \mathrm{~mm}$ lens, a nominal power of $48 \%$ was used to produce an average 0.028 " weld penetration (using ILT's true focus recommendations). From this work position, multiple snap plate welds were made at varying " $Z$ " displacements in 0.010 " steps from -0.140 to +0.140 inches. A new true focus setting was calculated, indicating close correlation but a negative offset of 0.010 inch from ILT's prescribed value. See Figure 3. The focus setting was adjusted to the new true focus to qualify parts.

Focus testing indicated a large depth-of-field for the $250 \mathrm{~mm}$ lens. Greater dispersion of penetration values was observed when moving away from the work vs. moving into the work, as is typical. A change of \pm 0.050 inch from true produced a minimal loss of about 0.001 inch in penetration. On average, about 0.010 inch degradation in weld penetration was noted at a bilateral defocus of 0.130 inch.

In comparison, the existing YAGs use $120 \mathrm{~mm}$ plano-convex lenses with a $70 \%$ shorter depth of field and are more sensitive to focus position. The fiber laser uses an AR-coated, achromatic doublet lens. These lenses are nearly free from aspherical aberration and coma. Compared with singlet lenses, achromatic lenses have superior optical performance. 


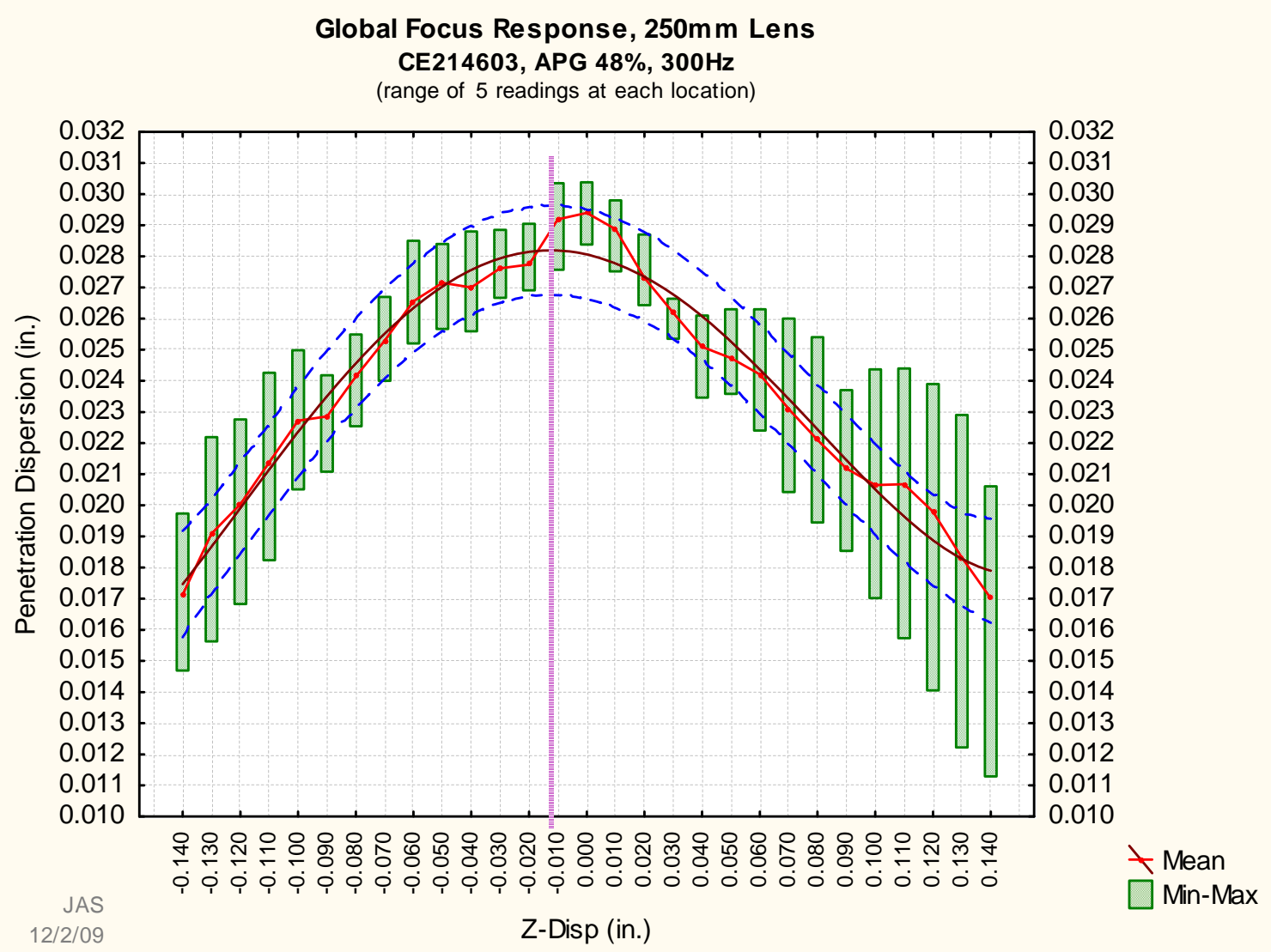

Figure 3. Focus Characterization

\section{Welding Experimentation}

Since equivalent performance to the old equipment was paramount with the Fiber laser, efforts were made to duplicate previous settings and wave shapes as much as possible.

The existing Nd:YAG, GSI JK802, laser equipment in the departments uses a sinusoidal modulated output at $300 \mathrm{~Hz}$ with $50 \%$ depth. The need for a modulated output presented an initial problem for the fiber's CW-only output.

On recommendation of the fiber laser manufacturer, an Arbitrary Pulse Generator (APG), fabricated by Dave Cimma LLC of Belchertown, MA, was incorporated to duplicate the modulated waveform values of the GSI, YAGs. The following is a description of the Cimma pulser from the equipment manual ${ }^{10}$ :

The APG is a software and hardware package that allows creation of arbitrary pulse shapes and sequences typically used for laser processing. Pulse shapes are defined by creating a series of data points, giving the time and amplitude of each point. Up to 128,000 data points can be used to define a single pulse shape. Each pulse definition consists of not only the shape data points, but also the operating mode desired for use: free-run, burst, single shot or CW. Along with that information is the pulse rate and burst count. By selecting a pulse definition, all operating parameters are set. An external interface provides full remote control of pulse definition selections and APG functions via the CNC or other control system. Selection of one of seven pulse definitions, remote analog scaling of the pulses and various user-definable I/Os for welding is possible. 


\section{Design-of-Experiment (DOE)}

Welding experimentation replicated feed rates using values of 80 IPM for butt seams and 70 IPM for fillet joints, typical of the Reset Rings. Whenever possible, equivalent power settings were employed. Selected power levels fell within limits of the old range. To enhance robustness at the Lower Specification Limit (LSL), slight upwardly biasing of power levels was incorporated, as has been discussed. Setting many parameters to the old constant levels simplified the analysis. Only the behavior of weld penetration as a function of power and machine percentage output remained to be characterized.

The linearity of power (W) by "\%" Power output was initially tested for comparison to the existing lasers. The GSI equipment has less-than-perfect linear output due to confocal regions where the output tend to "flatten" over small power ranges disrupting the response. The fiber laser had been reported as having near perfect linearity so, initially, the power vs. \% output response was tested to verify the claimed performance. The response is shown in Figure 4. The regression analysis indicated a surprisingly good response with a near perfect algorithm approaching $R^{2}=1$.

\section{\% Power vs. Power}

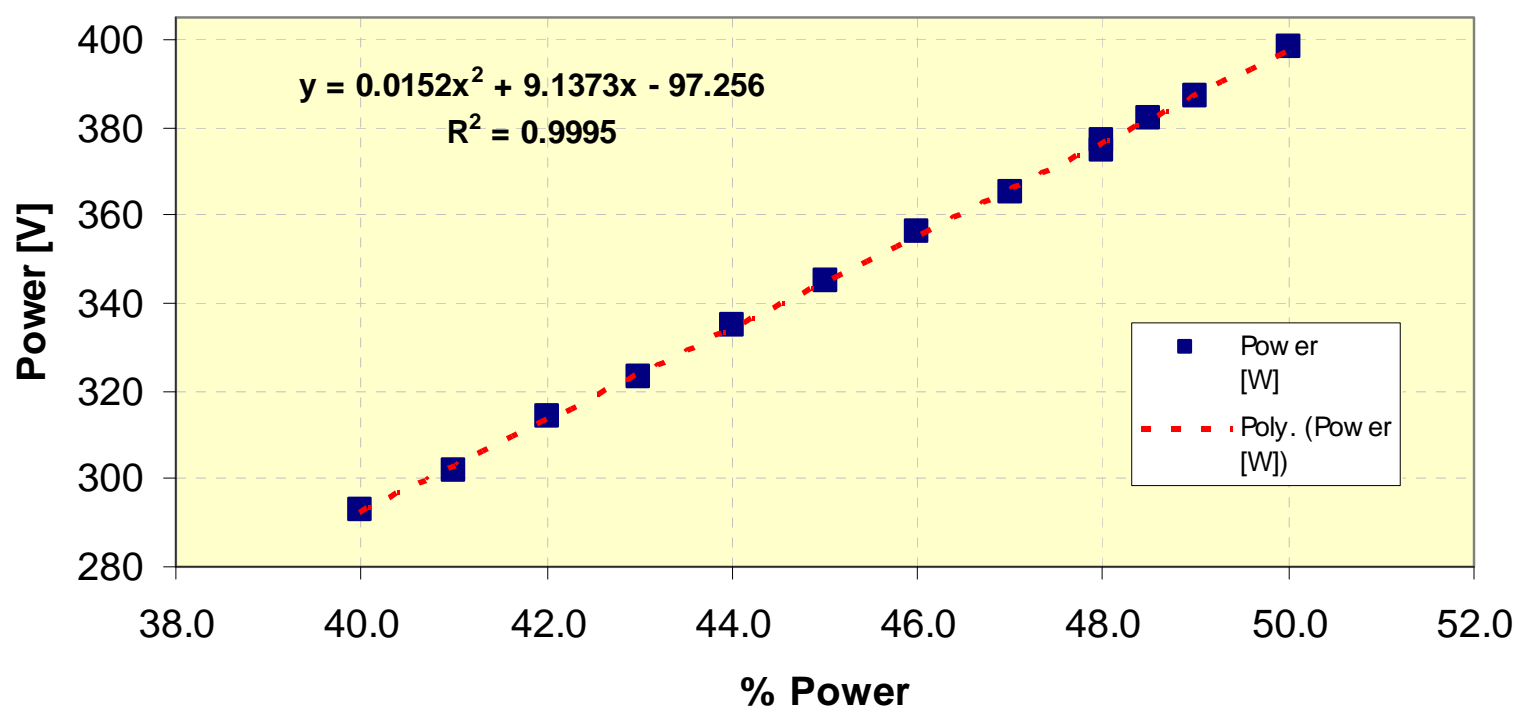

Figure 4. Power Output by Output \% Setting Showing Excellent Linearity

Power output "\%", the programmed value for the fiber laser, became the only parameter that was varied, facilitating the characterization activity. Power output was captured using an Ophir-Spiricon, water cooled meter, model \#L1500W. The model \#L1500W has a manufacturer's reported accuracy of $\pm 5 \%$.

The IPG's built-in internal meter is unsuitable for measuring modulated power due to its fast response. Further, the lack of a shutter and beam dump discouraged its use, typically requiring an absorptive metal mass as a "beam dump" substitute. The thermal pile Ophir averages the power over time and is suitable for modulated power measurements.

The initial power "\%" range of $40 \%-50 \%$ was chosen from previous screening tests done at the vendor, which had indicated usable penetration for the Firing Set welds. 
A sinusoidal modulation of $300 \mathrm{~Hz}$ and close to $50 \%$ depth, same as the YAGs, was programmed into sector " 4 " of the Cimma pulser and held constant.

Both penetration and width responses by "\%" power were charted, in accordance with Figures 5 and 6. Each point represents an average of four measurements per snap plate.

Good linearity is noted as evident by a high $\mathrm{R}^{2}$ of .9932 , suggesting the algorithm is acceptable as a predictor of values.

\section{\% Power vs. Avg Penetration}

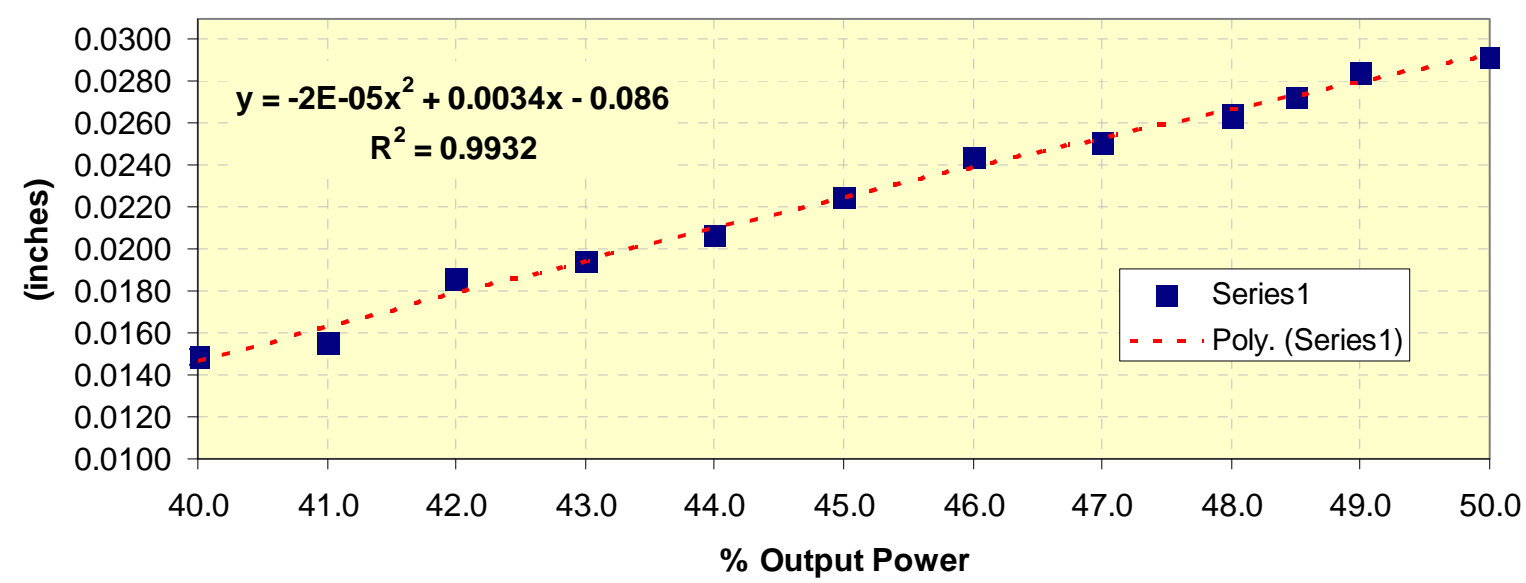

Figure 5. Output Power \% by Weld Penetration, S/Ps

$\%$ Power vs. Width

Speed: $80 \mathrm{in} / \mathrm{min}, \mathrm{Vp}-\mathrm{p}: \mathbf{8 0 0 V}$, Offset: $1000 \mathrm{~V}, 250 \mathrm{~mm}$ lens, S/ Ps

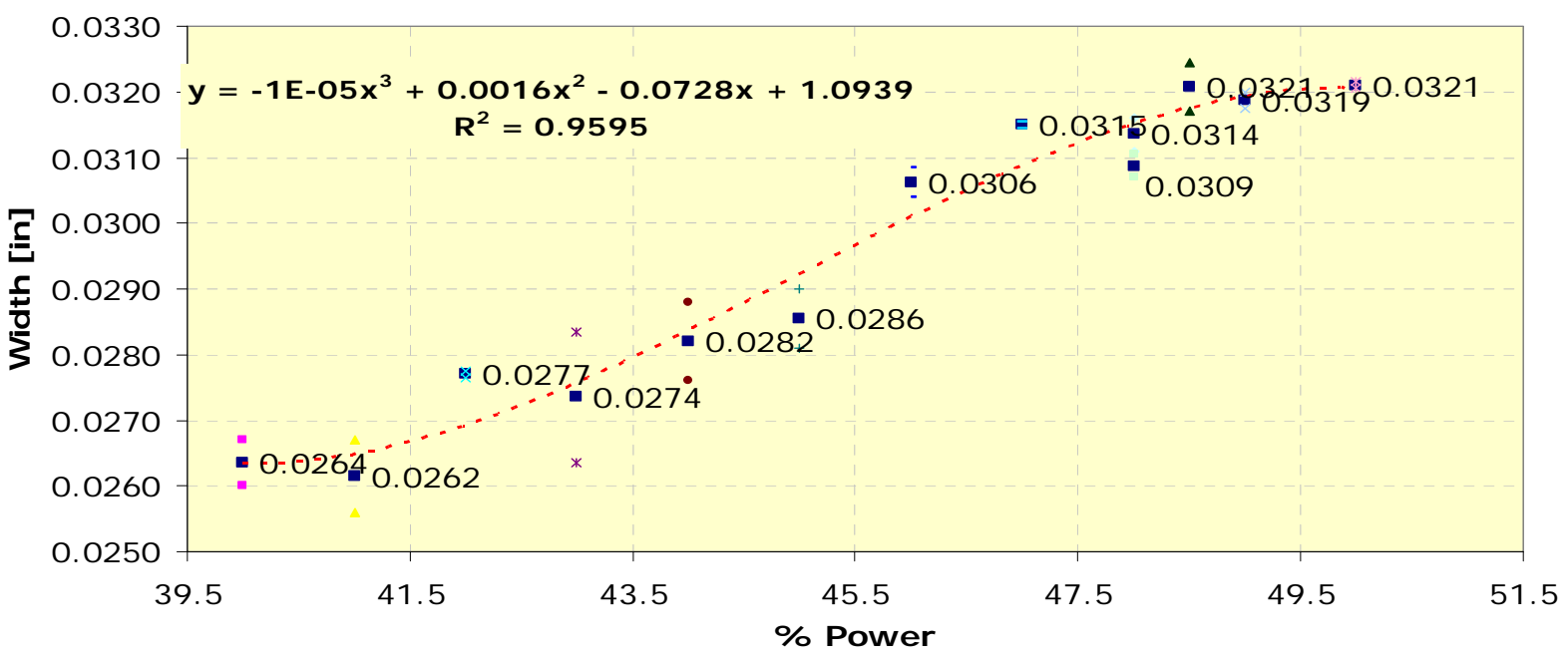

Figure 6. \% Power by Weld Width, S/Ps 
A more extensive penetration by actual power (wattage as read from the Ophir meter) was generated next, covering a longer period of about 6 weeks. Additional interim power values and multiple trials were charted with a broader range of 129 penetration readings. This exercise was a first-attempt to establish laser repeatability over time. The data was also reduced to determine the predicted interval (PI) at a $95 \%$ confidence level, as captured by the dashed line interval in Figure 7.

The PI represents worst case values expected from the response over $\pm 3 \sigma$ distribution. From the chart, a PI interval of $\sim \pm 0.0015$ " is predicted, suggesting a standard deviation for the S/Ps of 0.0005 inch.

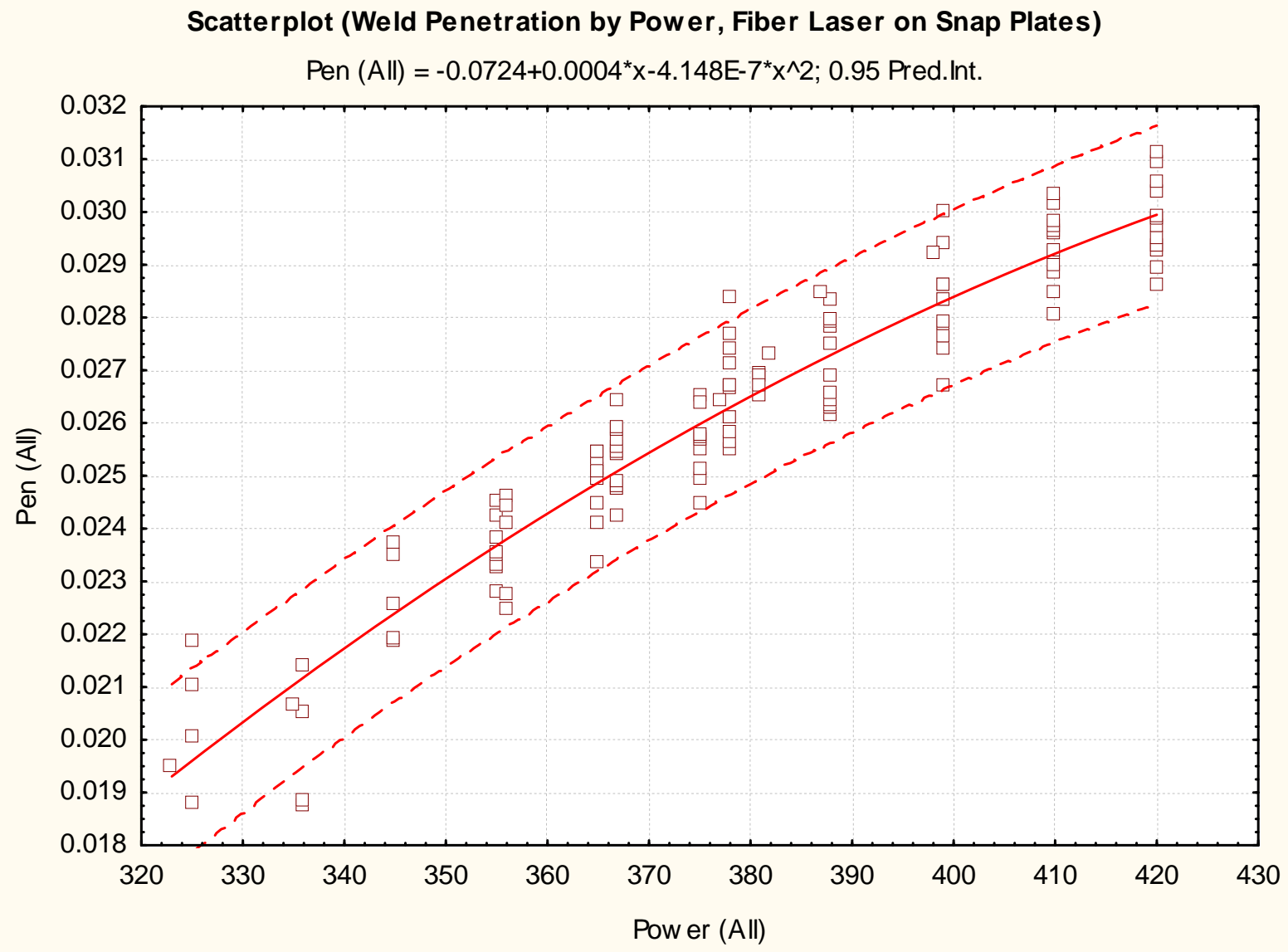

Figure 7. Extended Penetration Testing by Power in Watts, S/Ps, Showing a PI

\section{Welding of Qualification Parts}

Using the Figure 7 chart values, a power value of $48.5 \%$ or $\sim 385 \mathrm{~W}$, yielding about 0.027 inch was selected to weld qualification parts. These power and weld penetration levels correlate closely with existing YAGs parameters as used for production welding.

Initial simulated sample trial welds on samples using the chosen $48.5 \%$ produced penetration values that were 0.0015 inch higher than those measured on the S/Ps, indicating a negative S/P-to-SIM penetration shift. See "Sample Means" in Figures 8 and 9. A downward correction to $48 \%$ to lower the penetration was made. The new setting reduced the overall nominal penetration to $0.0281 \mathrm{inch}$, the value used going forward to weld qualification samples. 
Twenty combined weld sections taken from Reset Rings (butt), J3, J7, J8 and Launch Accelerometer welds produced a standard deviation of 0.00153 inch. See Figure 8, "Non-TSL Seam Welds Process Capibility."

\section{Process Capability Charts for Butted Seams and S/Ps}

Graphical representations of process capabilities for the combined butt joints and for S/Ps are shown Figures 8 and 9. In all cases, an Anderson-Darling normality test was completed first and verified normality for the distribution of values. For the non TSL seams, an expected overall performance of 2.72 PPM is predicted. Zero PPM is predicted at the low limit. For the S/Ps, zero PPM loss is predicted at the lower limits. The specification minimum penetration for $\mathrm{S} / \mathrm{Ps}$ is defined as 0.020 inches unilaterally with respect to the low limit.

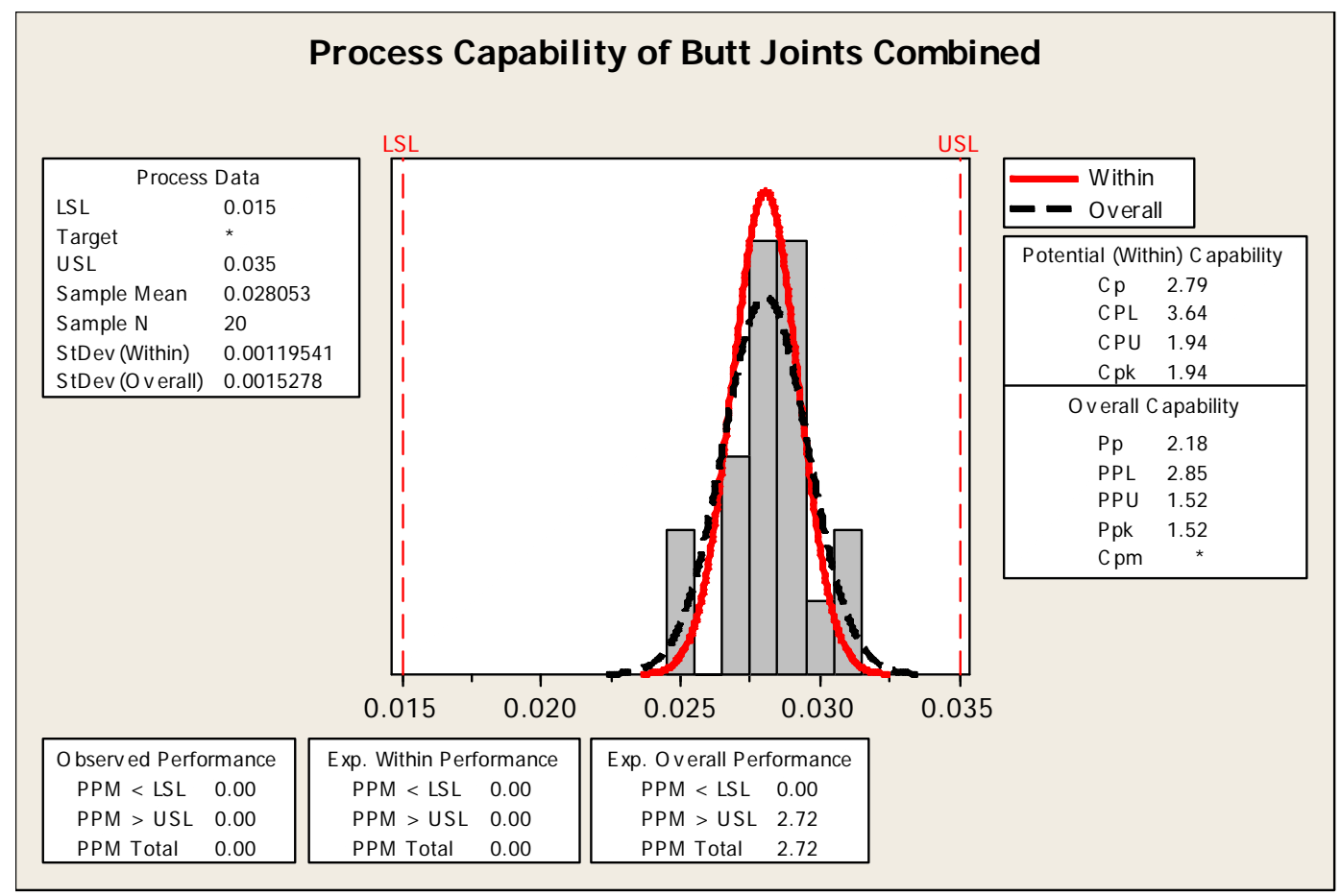

Figure 8. Non-TSL Seam Welds Process Capability 


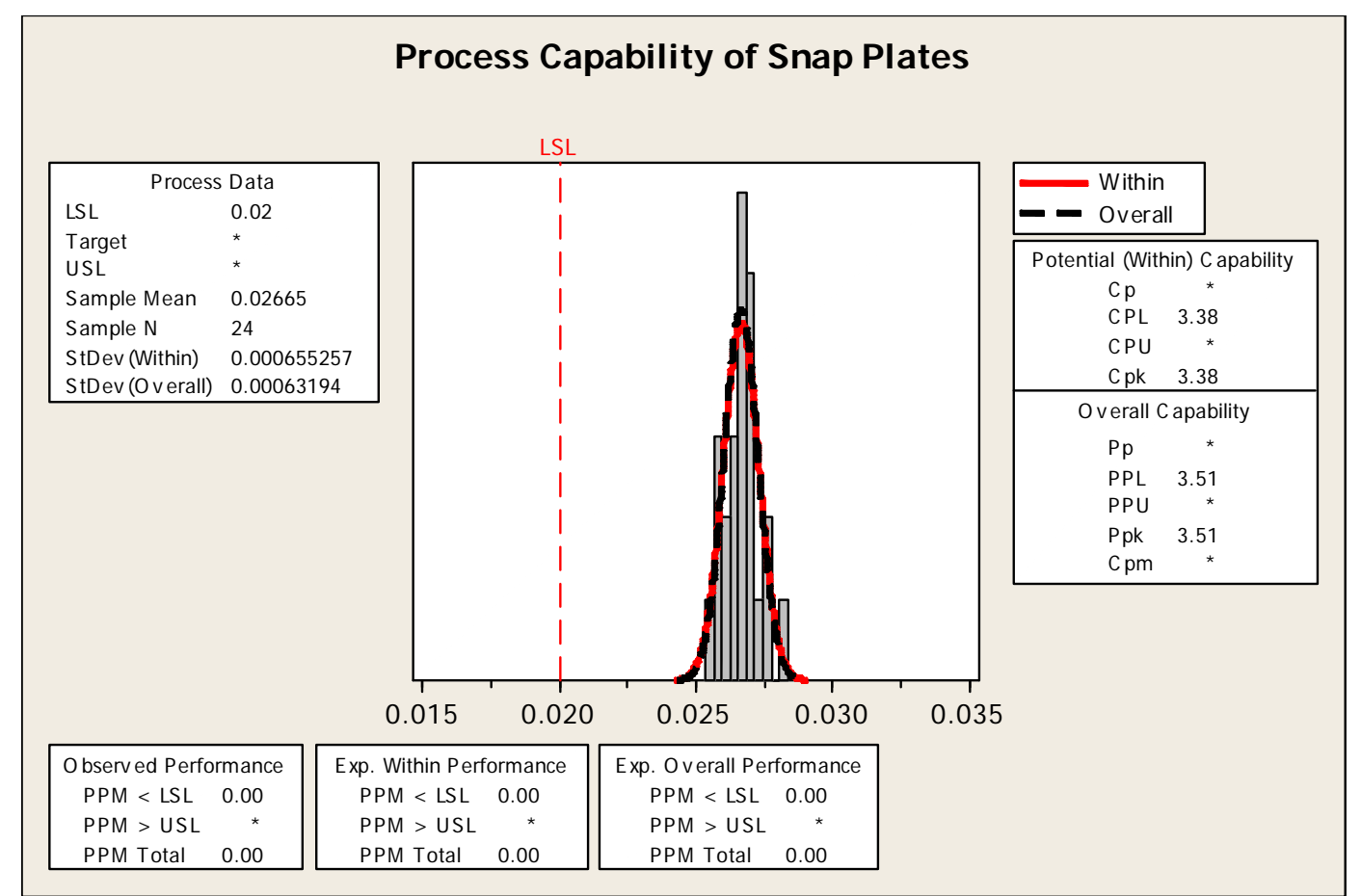

Figure 9. Snap Plates Process Capability

\section{TSL Qualification Welds}

Due to the Fiber laser's lower divergence and smaller raw beam diameter, perpendicular access to the TSL recessed joint is made possible. This characteristic facilitates processing and eliminates "canting", which is required with the GSI YAGs to provide beam clearance for a wide beam cone of $24^{\circ}$. In contrast, the Fiber's $2.8^{\circ}$ included angle easily accesses the recessed TSL joint without interference. An excellent $\mathrm{M}^{2}$ value and good coupling characteristics permit the use of a $250 \mathrm{~mm}$ lens to provide clearance vs. the shorter $120 \mathrm{~mm}$ for the GSI lasers. The comparison below compares YAG vs. fiber beams on the TSL joint. The YAG beam without "canting" interferes with the wall. The narrower fiber beam profile easily clears the side wall.

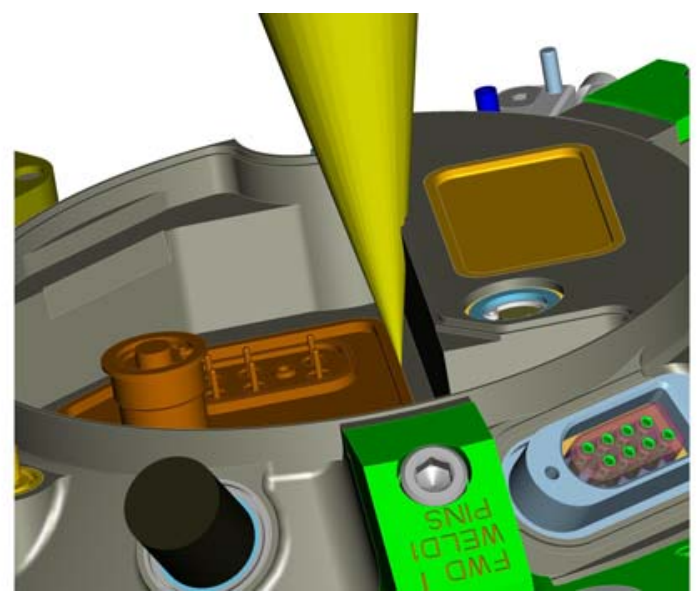

Figure 10. GSI YAG Beam Geometry

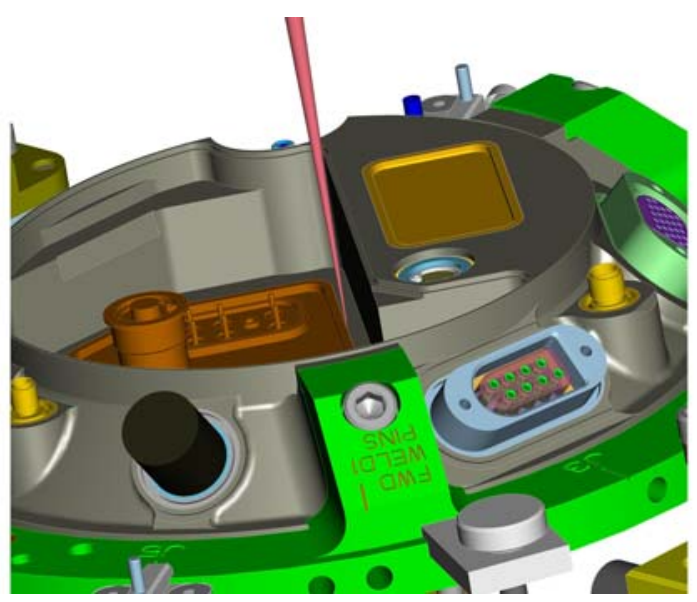

Figure 11. IPG Fiber Beam Geometry 
The TSL penetration requirement is unique due to its lower specified range of $0.010-0.030 \mathrm{inch}$. With the YAGs this weld was made at the same power but with lower penetration efficiency due to the angled access. With a new 90-degree access, a lower power selection was possible and cooler weld temperatures for the TSL should result. Referencing the S/P penetration in Figure 5, a power level of $\sim 45 \%$ in the range of 340 to 350 watts was selected to achieve $\sim 0.022$ inch weld penetration.

To validate the weld setting on actual parts, a scrapped TSL and simulated sample were welded with multiple segments using varying power "\%" levels from $41 \%$ to $48 \%$. The penetration responses are shown in Figure 12 along with the corresponding S/P data. Approximately +0.001 inch shift from S/P to product is noted. A value of $45 \%$ was chosen to achieve $\sim 0.022$ inch penetration overall on the qualification parts. Figure 12 shows the penetration response with corresponding weld width in inches.

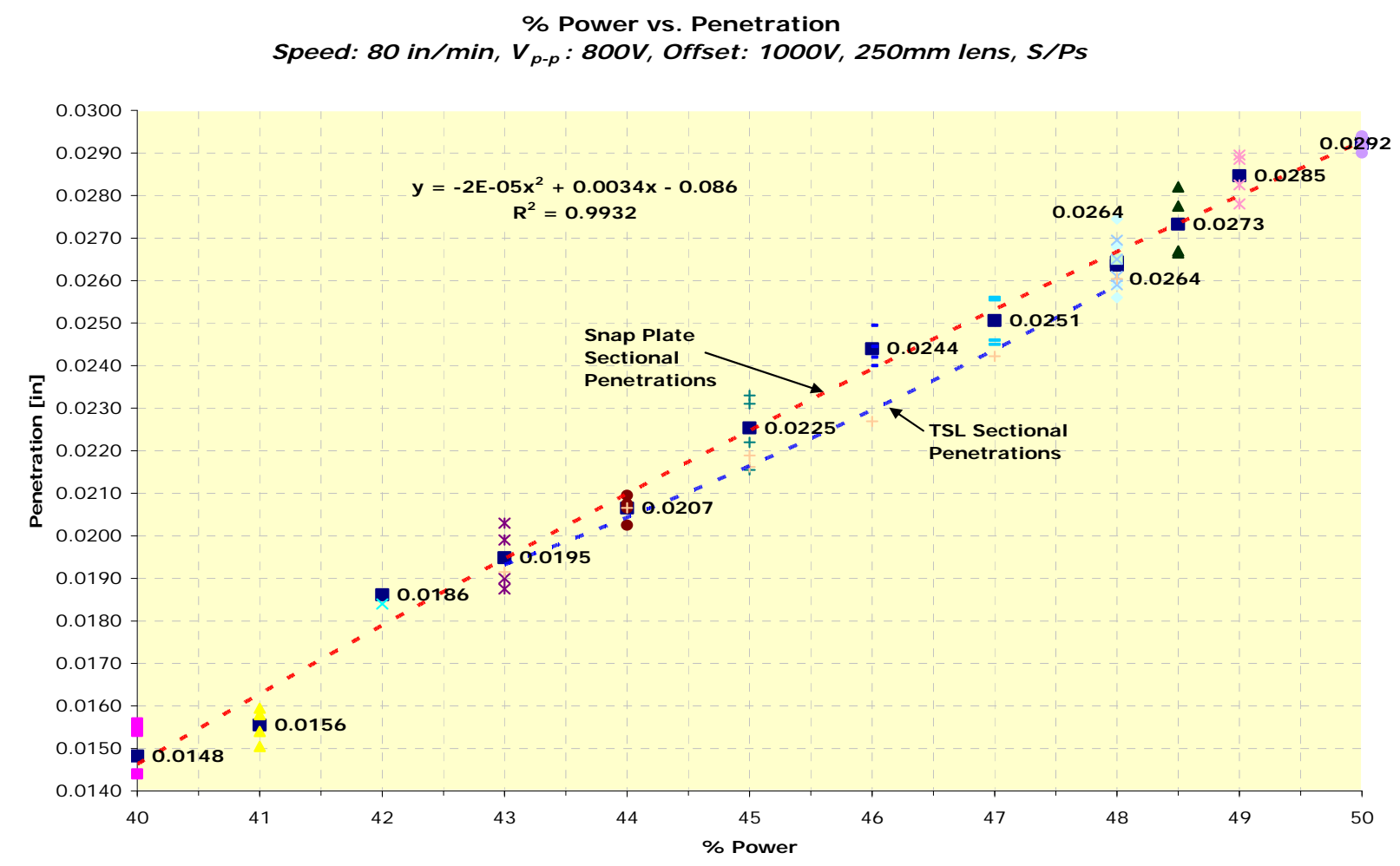

Figure 12. TSL Penetration for Various Power $\%$ as Measured on a Simulated Part

\section{TSL Qualification Parts Welding}

For qualification, two VAR TSL housings were welded onto two VAR 1A1067 Firing Set housings. Seven sections were taken from the weld periphery as follows: two each from the long sides and one each from the shorter segments. The fourteen penetration values obtained were analyzed for process capability, as shown in Figure 14. Robust process capability and a predicted performance of zero PPM rejects are predicted. The overall standard deviation for penetration for the qualification samples is $0.001285 \mathrm{inch}$, which is under the value of the combined joints. 


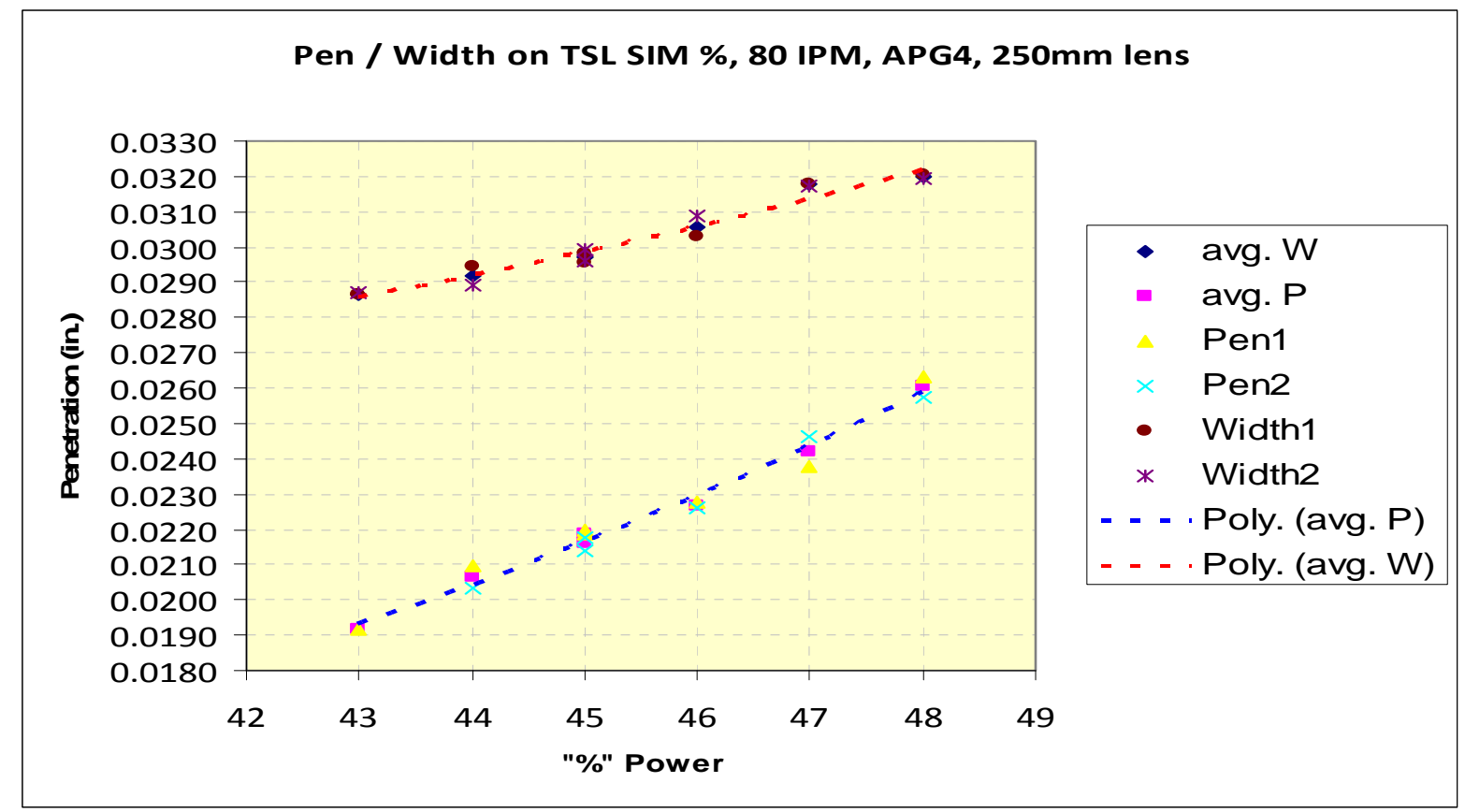

Figure 13. TSL Penetration and Width from Simulated TSL Part with Segmented Welds

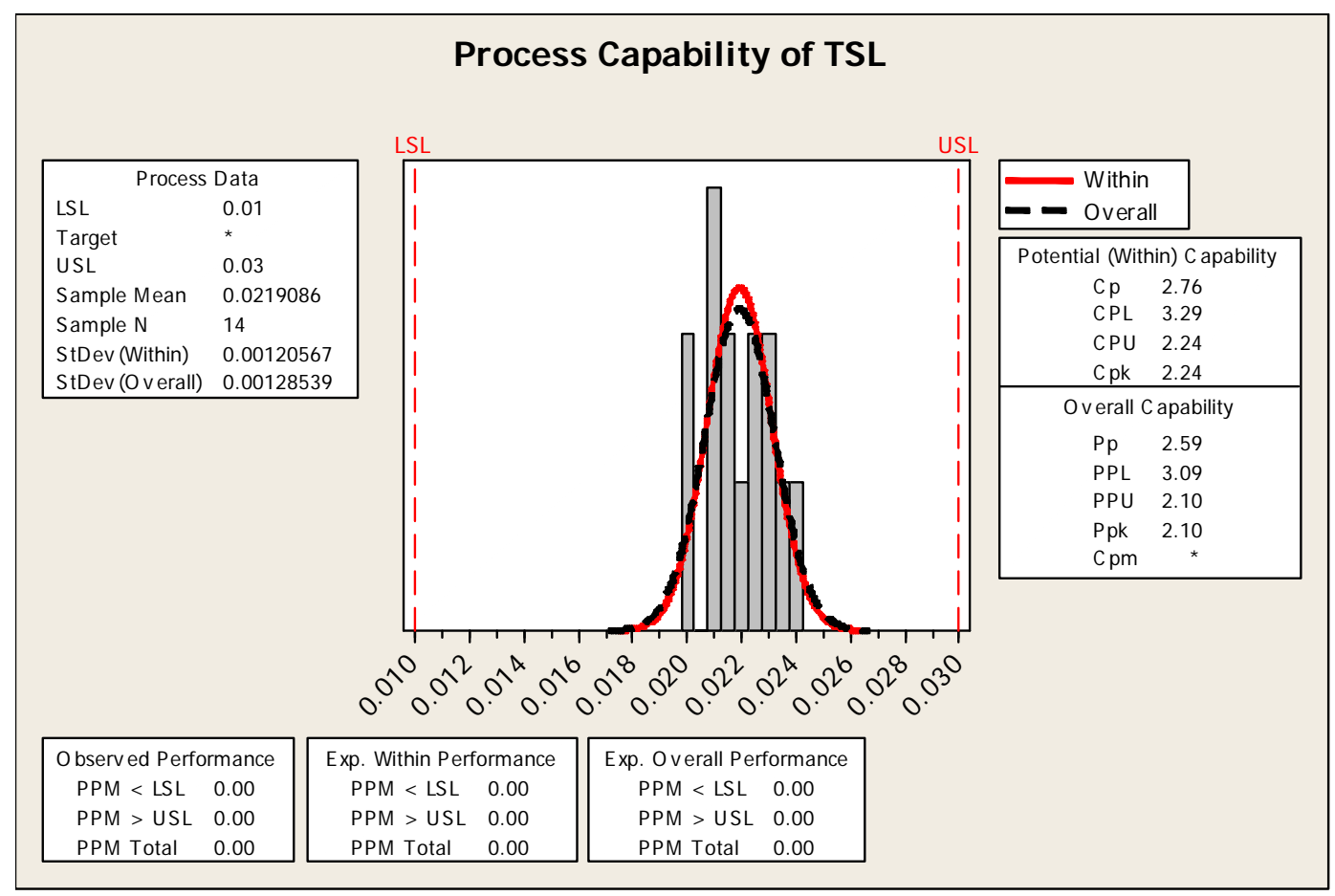

Figure 14. TSL Process Capability of Qualification Welds

\section{Process Capability of Reset Ring Fillets}

Two ISL Reset Rings were welded, sectioned and analyzed for process capability resulting in eight fillet and eight butt sections. 
The butt sections were included in the Figure 8 "mix", Process Capability of Butt Joints Combined. Penetration results and process capability of the Reset Ring fillets are shown in Figure 15. The process capability analysis utilized the recently relaxed fillet lower limit of 0.008 inch, ref. ACO 20092603SA.

The Figure 15 histogram uses a unilateral boundary low limit. The nominal fillet "throat" for the group is calculated as 0.0121 inch with a 0.00077 inch standard deviation. Capable process performance is reflected with an overall Ppk of 1.76 sigmas, indicating a mean value that is more than 5-standard deviations away from the lower specification limit.

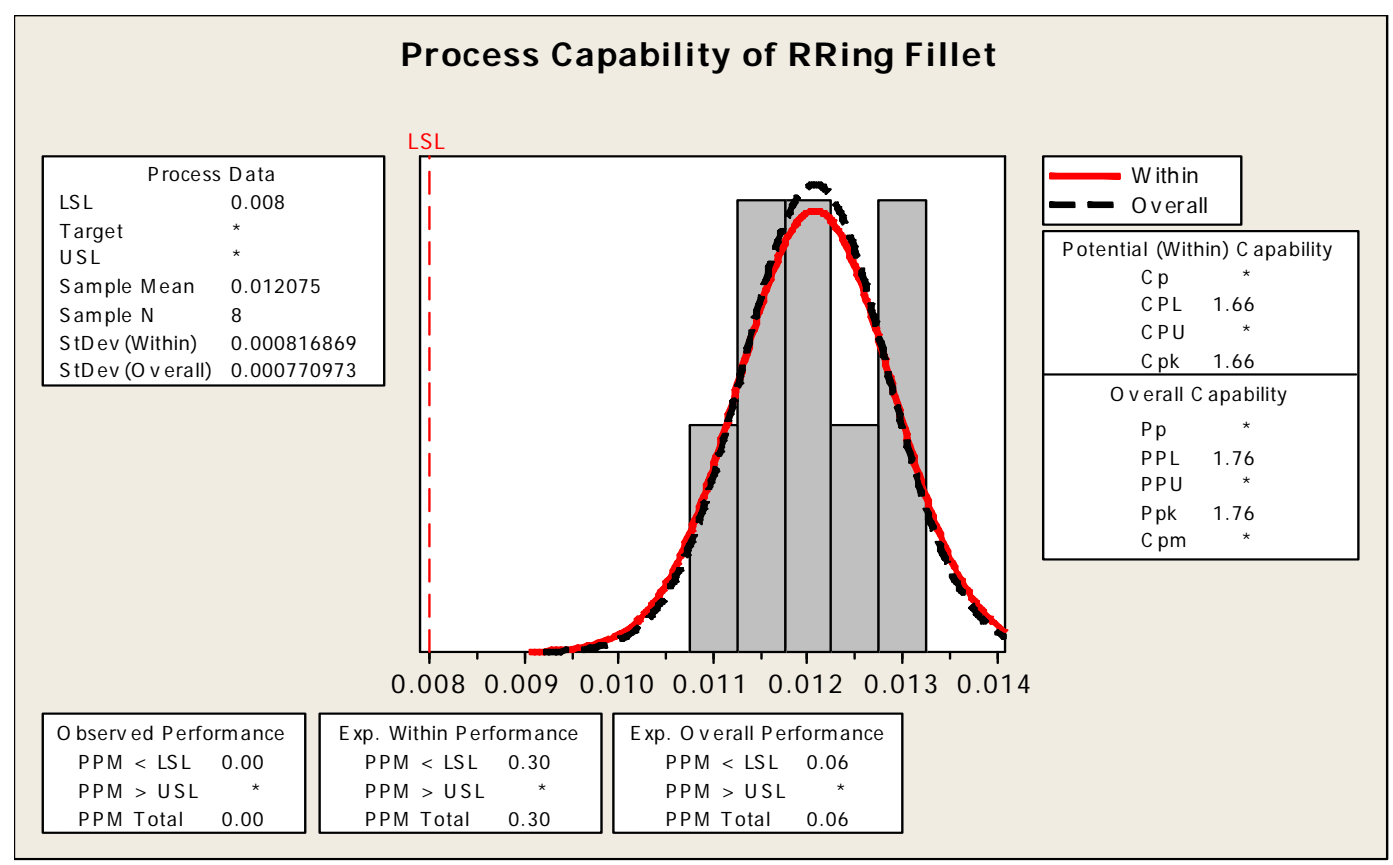

Figure 15. Process Capability of the Reset Rings

\section{$\underline{\text { Ground Strap and Flatness Cover Weld Parameter Selection }}$}

A 2-level, 2-factor, DOE with center point was completed to assess spot welding performance for the Ground Strap and Flatness Cover applications, both of which use the same parameters. The screening work narrowed settings to the below ranges of "\%" and "Pulse Time" duration. Single spots are utilized. With the Ground Strap, five minimum overlapping spots are used.

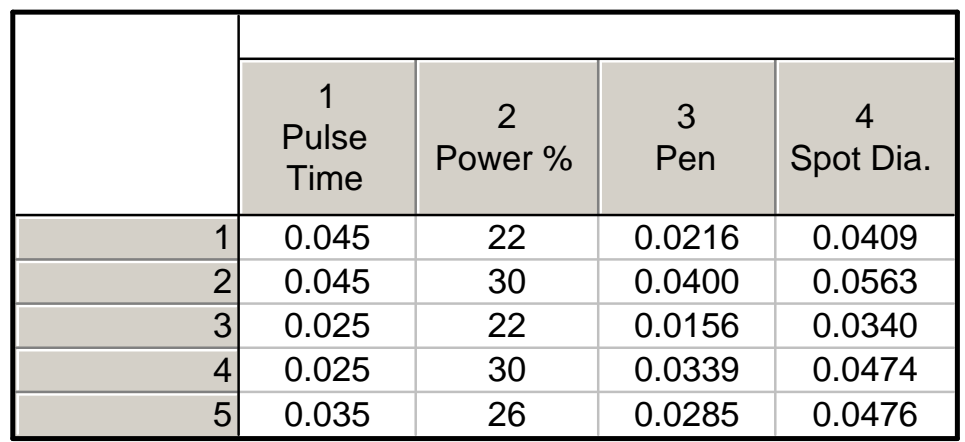

Table 2. DOE Matrix with Range of Parameters Used and Captured Response

The above DOE was analyzed and responses charted capturing penetration and spot diameter as function of "\%" and pulse time per Figures 16 and 17. 


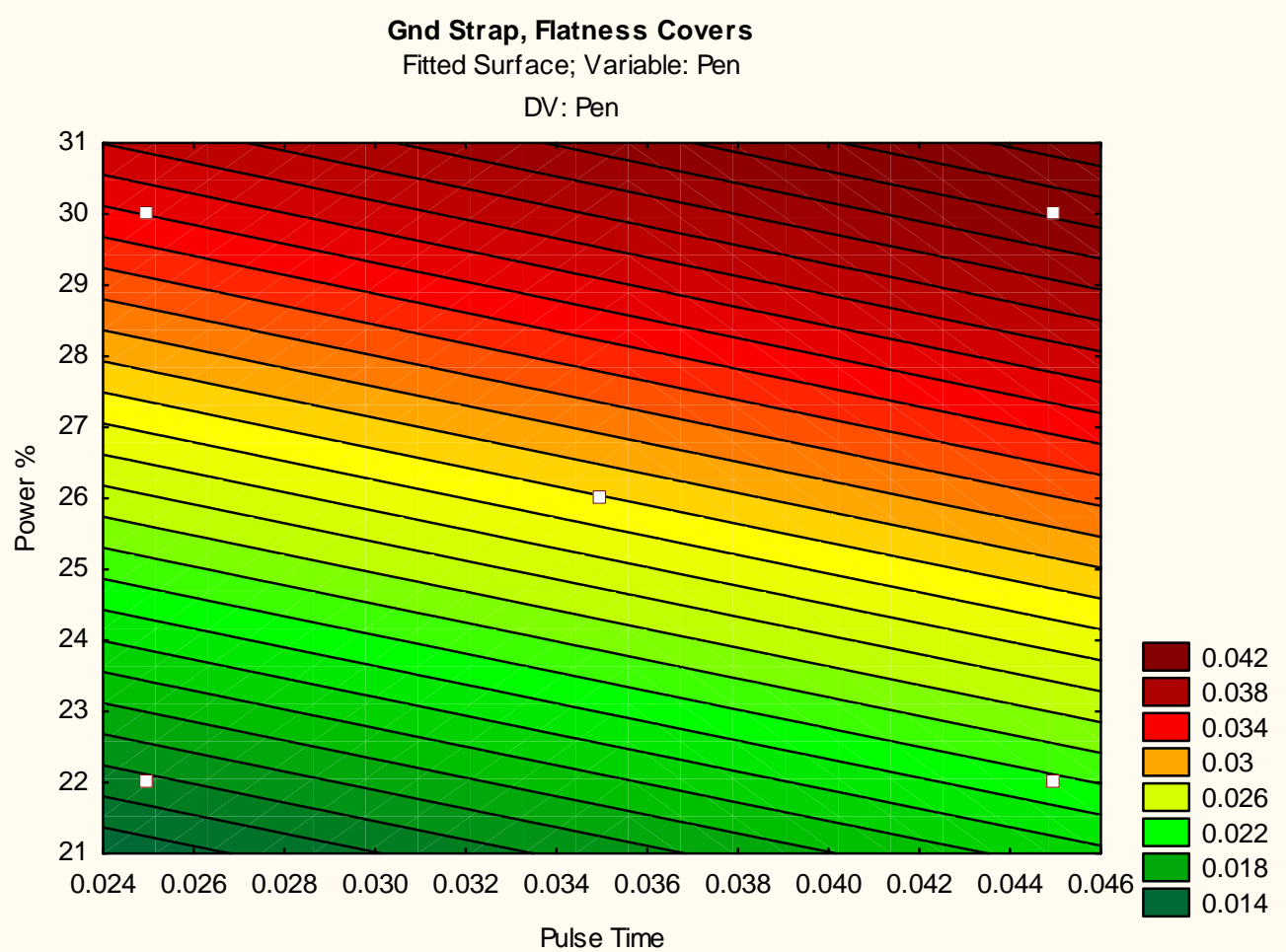

Figure 16. Ground Strap and Flatness Covers Penetration by \% and Pulse Duration

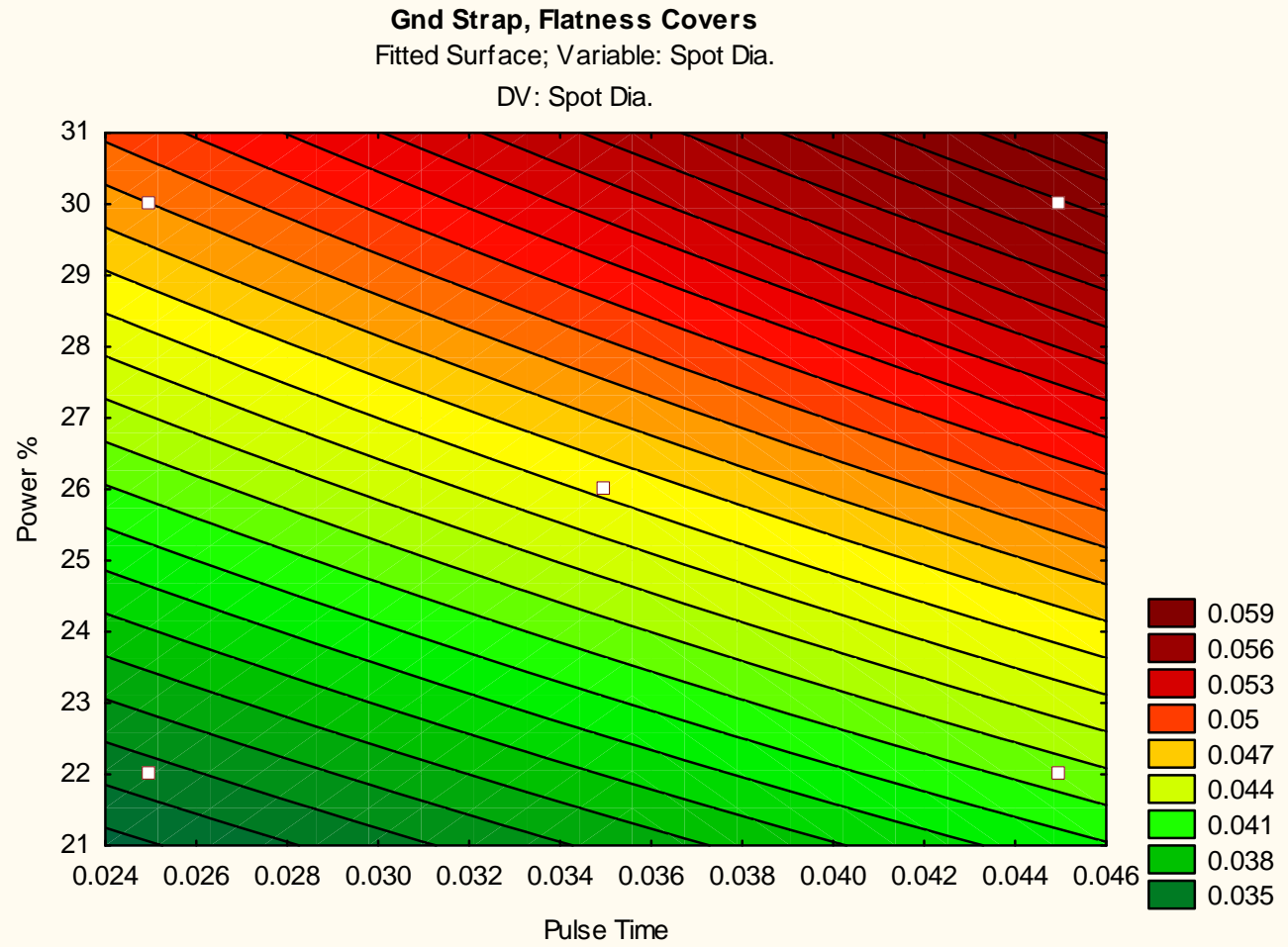

Figure 17. Ground Strap and Flatness Covers Spot Diameter by \% and Pulse Duration 
From the response, a central parameter was selected with $0.035 \mathrm{sec}$ "on" time and a "\%" setting of 26. Pareto analysis of the data indicated "power" as the most significant parameter affecting penetration. Penetration for the nominal setting was measured at 0.028 inch.

\section{Process Capability Summary}

Table 3 shows the potential and overall capabilities for the qualification parts for combined geometries of "non-TSL" joints, TSL welds and Reset Ring fillets as produced with the Fiber laser.

PPL, PPU and Ppk values are presented, which are measures of overall process capability, calculated with overall process standard deviation. They measure the distance between the process average and the specification limits, compared to the process spread as follows:

- PPL measures how close the process mean is to the lower specification limit

- PPU measures how close the process mean is to the upper specification limit

- Ppk equals the lesser of PPU and PPL.

The "worst" case Ppk process capability of 4.56 sigma limit is exhibited by the butt joints combined, nonTSL seams, which specify 0.025 inch as nominal. However, with respect to the Lower Specification Limit (LSL), this capability is enhanced due to uncentering, which favors the low limit with a very robust PPL of 8.55-sigmas. Early on it was explained that a larger and more capable process margin to the LSL is highly desirable to optimize process robustness for the /S/ criteria, which is applicable only against the LSL.

The TSL welds exhibit better process capability with Ppk of 2.1 and a sigma level of 6.63 standard deviations. The Reset Ring fillets are likewise robust. They only have a lower limit requirement and display a sigma level of 5.28 .

These figures predict the expected performances in terms of potential fallout from the process with the worst case being 2.72 PPM. This is a significant improvement over historical PPM for the YAGs, which originally exhibited 275.18 PPM for combined butt joints ${ }^{11}$.

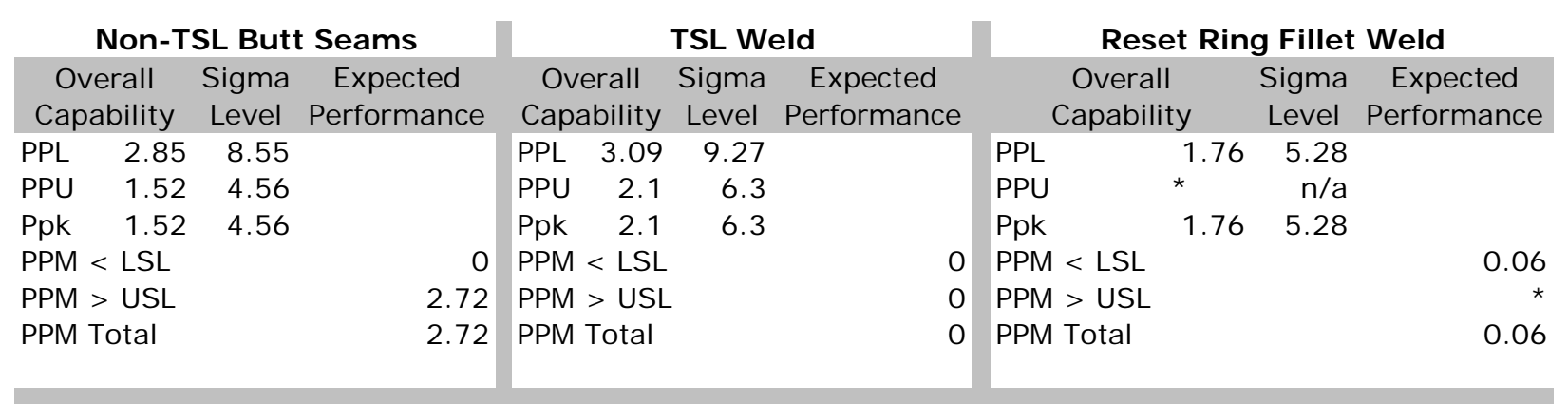

Table 3. Fiber Laser Process Capability and Expected Performance

\section{Secondary Attachment Pins Parameter Selection}

A screening DOE was initially completed to verify welding conditions at multiple "\%" power and pulse time settings. Pulsing with the fiber is done in the CW mode by temporally switching the cavity for the programmed pulse duration. 
Welds were made using Table 4, indicating the range of parameters. Metallography of welded pins indicated excessive base penetration above the $30 \%$ power value so the initial screen was discarded in favor of using only the lower power selection of $25 \%$, which produced optimum appearance and the least spatter.

\begin{tabular}{|cccccc|}
\hline I.D & "\%" & Pulse Time (sec) & IPG (W) & Ophir (W) & Comments \\
1 & 35 & 0.035 & 816 & 625 & spatter \\
2 & 25 & 0.035 & 545 & 417 & best \\
3 & 35 & 0.025 & 816 & 625 & spatter \\
4 & 25 & 0.025 & 545 & 417 & best \\
5 & 30 & 0.030 & 679 & 521 & spatter \\
\hline
\end{tabular}

Table 4. Pins Screening DOE Matrix

A second excursion of parameters was made based on the appearance of the first screen. The second group held power constant at $25 \%$ with "on" times shifted between $0.025 \mathrm{sec}$ and $0.040 \mathrm{sec}$ to achieve the desired visual appearance with good surface coverage and pin-to-TSL "bridging". The high value of .040 sec was selected based on nugget size and compliance to the penetration criteria for fillet and base numbers. Also, weld size was verified for robustness to accommodate large pin-to-housing gaps. Many of the samples exhibited significant gaps of up to 0.008 inch from misalignment of the mating holes forcing use of small pin diameters.

Results are per the below, Table 5. All values are in compliance to SS1A4542.

\begin{tabular}{|c|c|c|c|c|c|c|}
\hline I.D & "\%" & Pulse Time (sec) & Ophir (W) & "Throat" & Base & Comments \\
\hline 1 & 25 & 0.025 & 417 & 0.0172 & \multirow{13}{*}{$\begin{array}{l}\text { fused } \\
\text { fused } \\
\text { fused } \\
\text { fused } \\
\text { fused } \\
\text { fused } \\
\text { fused } \\
\text { fused } \\
\text { fused } \\
\text { fused } \\
\text { fused }\end{array}$} & \multirow{13}{*}{ Oxidized } \\
\hline 2 & 25 & 0.030 & 417 & 0.0182 & & \\
\hline 3 & 25 & 0.035 & 417 & 0.0160 & & \\
\hline 4 & 25 & 0.040 & 417 & 0.0171 & & \\
\hline 5 & 25 & 0.040 & 417 & 0.0148 & & \\
\hline 6 & 25 & 0.040 & 417 & 0.0123 & & \\
\hline 7 & 25 & 0.040 & 417 & 0.0164 & & \\
\hline 8 & 25 & 0.040 & 417 & 0.0170 & & \\
\hline 9 & 25 & 0.040 & 417 & 0.0150 & & \\
\hline 10 & 25 & 0.040 & 417 & 0.0127 & & \\
\hline 11 & 25 & 0.040 & 417 & 0.0155 & & \\
\hline \multirow{2}{*}{\multicolumn{3}{|c|}{$\begin{array}{l}\text { avg. } \\
\text { std. dev. }(4-11)\end{array}$}} & & 0.0151 & & \\
\hline & & & & 0.0018 & & \\
\hline
\end{tabular}

Table 5. Final Value Range Selection

Positioning of the pins was selected to allow a gap between two groupings of overlapping spot welds, approximately 0.045 -inch in diameter each. Each grouping of spots contains seven spot welds spaced 0.007 " apart and positioned along the periphery of the pin's head and central to the thickness $(0.020$ inch), in accordance with the below graphic: 


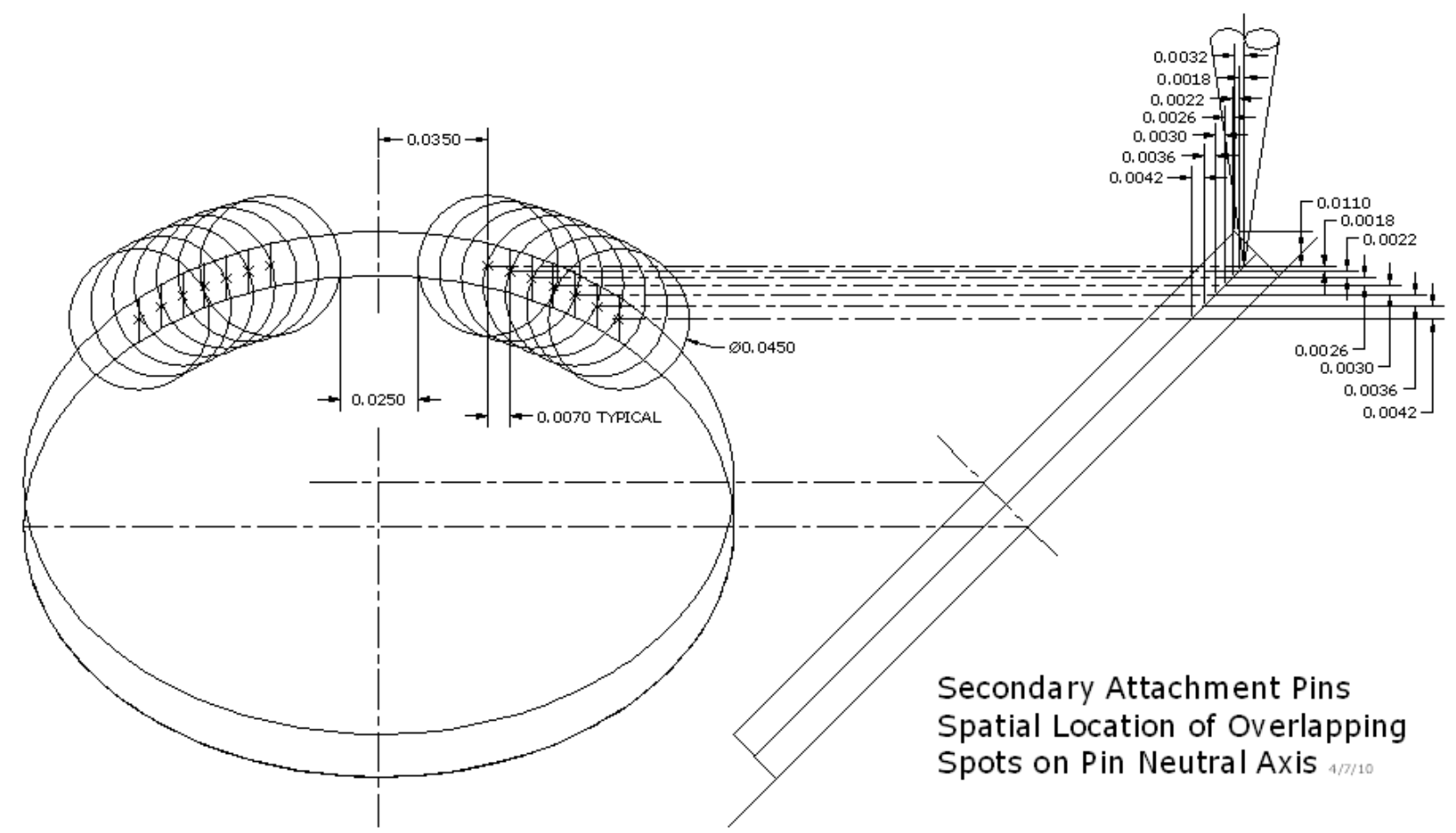

Figure 18. Placement of Spot Welds on Secondary Attachment Pins

\section{Process Capability of Secondary Attachment Pins}

Values from table 5 were analyzed and were confirmed to be normally distributed based on the Anderson-Darling test. Process capability was subsequently calculated using a Lower Specification Limit (LSL) of 0.010-inch with results per the below Figure 19. The expected Overall Performance shown is 1125.91 PPM (PPL, 1.03), which equates to about $0.1 \%$ potential fallout from the process. This application reflects the least capable process for the welds shown in this report or a process with slightly over 3-sigma standard deviations from the mean. An LSL of 0.008 inch would increase the process capability, PPL to 1.37 , or over 4-sigma with an improved expected overall performance of 18.89 PPM. 


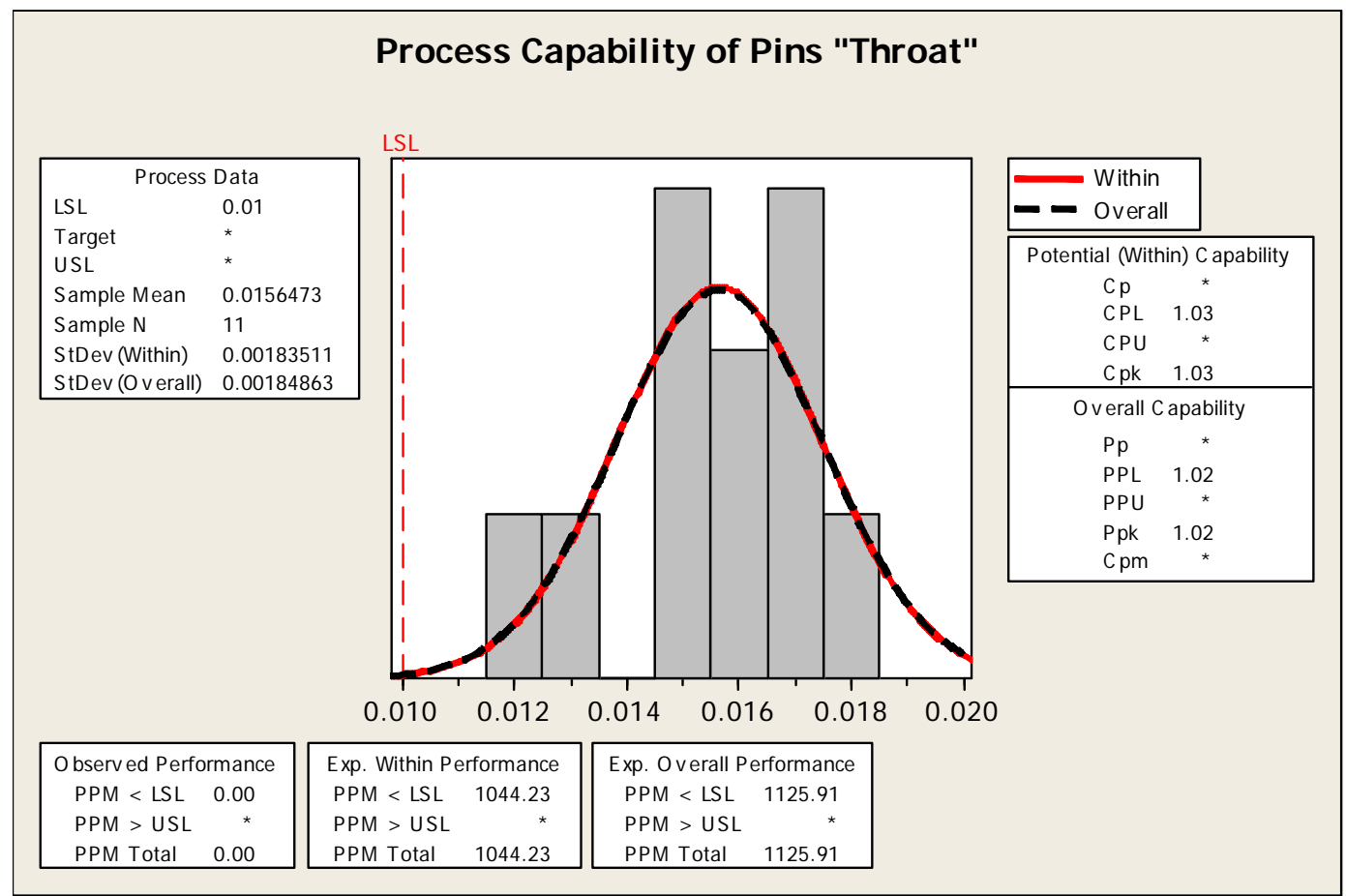

Figure 19. Process Capability of Secondary Attachment Pins

\section{ISL Thermal Testing}

A thermocoupled (TC) ISL was used to compare the YAG-to-Fiber thermal response. Previous data from the existing YAG lasers existed from this weld and could be used for comparison. TCs were placed at both long legs and one short leg of the ISL located approximately 0.080 inch from the weld and behind the ISL standing welded edge. Peak temperatures recorded from "Home" position and moving counter clockwise for TC\#1, TC\#2 and TC\#3 indicated 113,180 and $257^{\circ} \mathrm{C}$ respectively with an overall average of $183.7^{\circ} \mathrm{C}$ for the Fiber vs. $208^{\circ} \mathrm{C}$ for the existing YAGs based on previously recorded temperature data. See Figure 15, below.

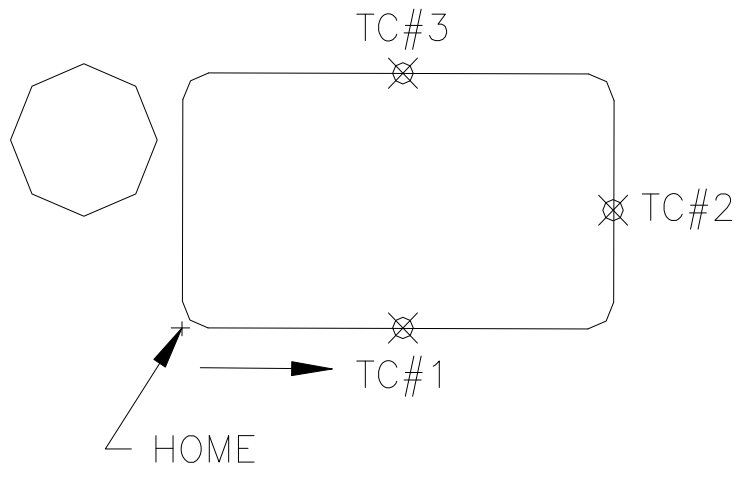

Figure 20. Orientation of Thermocouples and Weld Direction from "Home"

\section{Recommendations}

- Eliminate partial-penetration "square-groove" designs that require costly and strict tolerancing, flushness and edge breaks and which place the burden of penetration control on the equipment and the process. Because of limitations of the partial penetration scheme, often the dimensional definition and fit up of the parts themselves are not conducive to robust process capability. 
- Eliminate very tight tolerances for partial-penetration joints (as above) in favor of full penetration, backed-up joints with flange thicknesses that fit in counterbored "pockets" whose depths define the needed weld penetration.

- Unless critical upper-end boundary conditions exist for the product, call out only unilateral limits that allow the flexibility to select machine parameters that are robust to the minimum penetration limit. Bilateral dimensioning forces selection of centered machine parameters that may not be optimum for manufacturability.

- Flange thicknesses of "lap" welds should be sufficiently robust to accommodate the "throat" criteria. The throat requirement should never exceed $50 \%$ of the flange thickness. For typical Firing Set sizing of welds, the flange thickness should be kept to 0.020 inch maximum.

- Product tolerancing should allow at least 6-sigma (standard deviation limits) to either side of the mean value of the requirement based on the standard deviation of the specific equipment capability.

- Provide "product-based" criteria based on the functional requirement of each weld instead of "process-based" limits that reflect the equipment capability.

\section{Accomplishments}

- First-time use of a fiber laser for WR production of Firing Set and AF\&Fs at the KCP

- Penetration and dimensional criteria were met, which were compliant to SS1A4542 requirements

- Commissioning of equipment within a compressed time frame

- Characterization of temperature profiles for the ISL weld, indicating similar response with the existing YAG weld process

\section{Conclusion}

Based on the metallography, dimensional and visual results presented, CE214603, fiber laser, complies with the specifics of SS1A4542 for Firing Set production welding qualification. 


\section{References}

$1 \quad$ M. Mehl, "PDRD 703710, Fiber Laser Welds on Stainless", Honeywell Federal Manufacturing \& Technologies, 2007 - 2009.

2 M. Mehl, "Fiber Laser Weld Trials - Seam Welds, IPG Photonics", KCP/D8E3, Aug. 17, 2007

3 J. Samayoa, "Trip Report from IPG Photonics, Oxford, MA; June 17-18, 2008, and data analysis, dated August 25, 2008"

4 J. Samayoa, “Trip Report: Visit to Alabama Laser, Munford, AL”, 8/11-8/13/2008

5 J. Samayoa, "Data for D92 taken at ILT - Prelim. Acceptance of D77 Laser”, 7/6-10, 2009

6 J. Samayoa, "Trip Report, Ohio State Welding Center and Edison Welding Institute (EWI) Visit”, 7/16-17, 2009

7 Matt Reiter, "Partial Penetration Fiber Laser Welding on Austenitic Stainless Steel”, The Ohio State University, 2009

8 J. Samayoa, “Fiber ILT Welds Updated”, Excel Data, August 13, 2009

9 SS1A4542, Welding Requirements, MC4702 (U), Issue P, ACO20092603SA, C. F. Briner, SNLA 2625, A. Young, KC831, November 2009.

10 Dave Cimma, LLC, Arbitrary Pulse Generator (APG), Electronic Operating Manual; Belchertown, MA 01007

11 J. Samayoa, "Development of a Welding Capability for a Firing Set", KCP-613-8198, Honeywell Federal Manufacturing \& Technologies, September 2006.

12 J. Samayoa, "Development of a Backup Laser Welding Capability for a Firing Set", KCP-613-8387, Honeywell Federal Manufacturing \& Technologies, December 2007. 


\section{Appendix "A"}

Fiber Laser Qualification Results 


\begin{tabular}{|c|c|c|c|c|c|c|c|c|c|c|c|}
\hline \multirow[b]{3}{*}{ Group } & \multicolumn{11}{|c|}{ Fiber Laser Weld Qualification Results } \\
\hline & \multirow[b]{2}{*}{ Name / Section I.D. } & & & \multicolumn{3}{|c|}{$\begin{array}{l}\text { Weld } \\
\text { Penetration }\end{array}$} & \multicolumn{2}{|l|}{$\begin{array}{l}\text { Fillet } \\
\text { Penetration }\end{array}$} & \multirow[t]{2}{*}{$\begin{array}{c}\text { Width / } \\
\text { Spot Dia. }\end{array}$} & \multirow[t]{2}{*}{ Group Avg. } & \multirow[t]{2}{*}{$\begin{array}{l}\text { Date } \\
\text { Welded }\end{array}$} \\
\hline & & Part or Sample & LTR\# & Butt J oint & OOF & 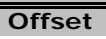 & Throat & Base & & & \\
\hline $\mathrm{n} / \mathrm{a}$ & $\mathrm{S} / \mathrm{P}$ & Snap Plate & & 0.0272 & $\mathrm{n} / \mathrm{a}$ & $\mathrm{n} / \mathrm{a}$ & $\mathrm{n} / \mathrm{a}$ & $\mathrm{n} / \mathrm{a}$ & & & \\
\hline $\mathrm{n} / \mathrm{a}$ & $\mathrm{S} / \mathrm{P}$ & Snap Plate & & 0.0257 & $\mathrm{n} / \mathrm{a}$ & $\mathrm{n} / \mathrm{a}$ & $n / a$ & $\mathrm{n} / \mathrm{a}$ & & & \\
\hline $\mathrm{n} / \mathrm{a}$ & $S / P$ & Snap Plate & & 0.0277 & $\mathrm{n} / \mathrm{a}$ & $\mathrm{n} / \mathrm{a}$ & $\mathrm{n} / \mathrm{a}$ & $\mathrm{n} / \mathrm{a}$ & & 0.0267 & \\
\hline $\mathrm{n} / \mathrm{a}$ & $\mathrm{S} / \mathrm{P}$ & Snap Plate & & 0.0283 & $\mathrm{n} / \mathrm{a}$ & $\mathrm{n} / \mathrm{a}$ & $\mathrm{n} / \mathrm{a}$ & $\mathrm{n} / \mathrm{a}$ & & & \\
\hline 1 & TSL1-1A & Part (hsg) / Part (TSL) & 60859 & 0.0242 & 0.0000 & $\mathrm{n} / \mathrm{a}$ & $\mathrm{n} / \mathrm{a}$ & $\mathrm{n} / \mathrm{a}$ & 0.0305 & & $2 / 9 / 2010$ \\
\hline 1 & TSL1-2A & Part (hsg) / Part (TSL) & 60859 & 0.0224 & 0.0000 & $\mathrm{n} / \mathrm{a}$ & $\mathrm{n} / \mathrm{a}$ & $\mathrm{n} / \mathrm{a}$ & $\mathrm{n} / \mathrm{a}$ & & $2 / 9 / 2010$ \\
\hline 1 & TSL1-1B & Part (hsg) / Part (TSL) & 60859 & 0.0198 & 0.0054 & $\mathrm{n} / \mathrm{a}$ & $\mathrm{n} / \mathrm{a}$ & $\mathrm{n} / \mathrm{a}$ & 0.0302 & & $2 / 9 / 2010$ \\
\hline 1 & TSL1-1C & Part (hsg) / Part (TSL) & 60859 & 0.0222 & 0.0030 & $\mathrm{n} / \mathrm{a}$ & $\mathrm{n} / \mathrm{a}$ & $\mathrm{n} / \mathrm{a}$ & 0.0303 & & $2 / 9 / 2010$ \\
\hline 1 & TSL1-2C & Part (hsg) / Part (TSL) & 60859 & 0.0215 & 0.0040 & $\mathrm{n} / \mathrm{a}$ & $\mathrm{n} / \mathrm{a}$ & $\mathrm{n} / \mathrm{a}$ & $\mathrm{n} / \mathrm{a}$ & & $2 / 9 / 2010$ \\
\hline 1 & TSL1-1D & Part (hsg) / Part (TSL) & 60859 & 0.0216 & 0.0030 & $\mathrm{n} / \mathrm{a}$ & $\mathrm{n} / \mathrm{a}$ & $\mathrm{n} / \mathrm{a}$ & 0.0311 & & $2 / 9 / 2010$ \\
\hline 1 & TSL1-1E & Part (hsg) / Part (TSL) & 60859 & 0.0212 & 0.0033 & $\mathrm{n} / \mathrm{a}$ & $\mathrm{n} / \mathrm{a}$ & $\mathrm{n} / \mathrm{a}$ & 0.0310 & & $2 / 9 / 2010$ \\
\hline 1 & TSL2-1A & Part (hsg) / Part (TSL) & 60859 & 0.0209 & 0.0026 & $\mathrm{n} / \mathrm{a}$ & $\mathrm{n} / \mathrm{a}$ & $\mathrm{n} / \mathrm{a}$ & 0.0310 & 0.0219 & $2 / 10 / 2010$ \\
\hline 1 & TSL2-2A & Part (hsg) / Part (TSL) & 60859 & 0.0201 & 0.0025 & $\mathrm{n} / \mathrm{a}$ & $\mathrm{n} / \mathrm{a}$ & $\mathrm{n} / \mathrm{a}$ & $\mathrm{n} / \mathrm{a}$ & & $2 / 10 / 2010$ \\
\hline 1 & TSL2-1B & Part (hsg) / Part (TSL) & 60859 & 0.0230 & 0.0025 & $\mathrm{n} / \mathrm{a}$ & $n / a$ & $n / a$ & 0.0302 & & $2 / 10 / 2010$ \\
\hline 1 & TSL2-1C & Part (hsg) / Part (TSL) & 60859 & 0.0208 & 0.0025 & $\mathrm{n} / \mathrm{a}$ & $\mathrm{n} / \mathrm{a}$ & $\mathrm{n} / \mathrm{a}$ & 0.0296 & & $2 / 10 / 2010$ \\
\hline 1 & TSL2-2C & Part (hsg) / Part (TSL) & 60859 & 0.0228 & 0.0030 & $\mathrm{n} / \mathrm{a}$ & $\mathrm{n} / \mathrm{a}$ & $\mathrm{n} / \mathrm{a}$ & $\mathrm{n} / \mathrm{a}$ & & $2 / 10 / 2010$ \\
\hline 1 & TSL2-1D & Part (hsg) / Part (TSL) & 60859 & 0.0235 & 0.0016 & $\mathrm{n} / \mathrm{a}$ & $\mathrm{n} / \mathrm{a}$ & $\mathrm{n} / \mathrm{a}$ & 0.0299 & & $2 / 10 / 2010$ \\
\hline 1 & TSL2-1E & Part (hsg) / Part (TSL) & 60859 & 0.0227 & 0.0010 & $\mathrm{n} / \mathrm{a}$ & $\mathrm{n} / \mathrm{a}$ & $\mathrm{n} / \mathrm{a}$ & 0.0300 & & $2 / 10 / 2010$ \\
\hline 2 & $J 71$ & Part (hsg) / Part (J 7) & 60853 & 0.0252 & 0.0050 & $\mathrm{n} / \mathrm{a}$ & $\mathrm{n} / \mathrm{a}$ & $\mathrm{n} / \mathrm{a}$ & $\mathrm{n} / \mathrm{a}$ & & \\
\hline 2 & 372 & Part (hsg) / Part (J 7) & 60853 & 0.0275 & 0.0010 & $\mathrm{n} / \mathrm{a}$ & $\mathrm{n} / \mathrm{a}$ & $\mathrm{n} / \mathrm{a}$ & $\mathrm{n} / \mathrm{a}$ & & \\
\hline 2 & 381 & Part (hsg) / Part (J 8) & 60853 & 0.0267 & 0.0000 & $\mathrm{n} / \mathrm{a}$ & $\mathrm{n} / \mathrm{a}$ & $\mathrm{n} / \mathrm{a}$ & $\mathrm{n} / \mathrm{a}$ & & \\
\hline 2 & $j 82$ & Part (hsg) / Part (J 8) & 60853 & 0.0285 & 0.0000 & $\mathrm{n} / \mathrm{a}$ & $\mathrm{n} / \mathrm{a}$ & $\mathrm{n} / \mathrm{a}$ & $\mathrm{n} / \mathrm{a}$ & & \\
\hline 2 & J 83 & Part (hsg) / Part (J 8) & 60853 & 0.0291 & 0.0020 & $\mathrm{n} / \mathrm{a}$ & $\mathrm{n} / \mathrm{a}$ & $\mathrm{n} / \mathrm{a}$ & $\mathrm{n} / \mathrm{a}$ & 0.0275 & \\
\hline 2 & 84 & Part (hsg) / Part (J 8) & 60853 & 0.0285 & 0.0050 & $\mathrm{n} / \mathrm{a}$ & $\mathrm{n} / \mathrm{a}$ & $\mathrm{n} / \mathrm{a}$ & $\mathrm{n} / \mathrm{a}$ & & \\
\hline 2 & J $3-1$ & Part (hsg) / Part (J 3) & 60853 & 0.0265 & 0.0000 & $n / a$ & $\mathrm{n} / \mathrm{a}$ & $\mathrm{n} / \mathrm{a}$ & $\mathrm{n} / \mathrm{a}$ & & $2 / 10 / 2010$ \\
\hline 2 & $3-2$ & Part (hsg) / Part (J 3) & 60853 & 0.0269 & 0.0000 & $\mathrm{n} / \mathrm{a}$ & $\mathrm{n} / \mathrm{a}$ & $\mathrm{n} / \mathrm{a}$ & $\mathrm{n} / \mathrm{a}$ & & $2 / 10 / 2010$ \\
\hline 2 & $3-3$ & Part (hsg) / Part (J 3) & 60853 & 0.0270 & 0.0000 & $\mathrm{n} / \mathrm{a}$ & $\mathrm{n} / \mathrm{a}$ & $\mathrm{n} / \mathrm{a}$ & $\mathrm{n} / \mathrm{a}$ & & $2 / 10 / 2010$ \\
\hline 2 & $3-4$ & Part (hsg) / Part (J 3) & 60853 & 0.0264 & 0.0000 & $\mathrm{n} / \mathrm{a}$ & $\mathrm{n} / \mathrm{a}$ & $\mathrm{n} / \mathrm{a}$ & $\mathrm{n} / \mathrm{a}$ & & $2 / 10 / 2010$ \\
\hline 3 & ISL Reset Ring, butt 1-1 & Part (hsg) / Part (ISL) & 60853 & 0.0278 & 0.0000 & $\mathrm{n} / \mathrm{a}$ & $\mathrm{n} / \mathrm{a}$ & $\mathrm{n} / \mathrm{a}$ & $\mathrm{n} / \mathrm{a}$ & & \\
\hline 3 & ISL Reset Ring, butt 1-2 & Part (hsg) / Part (ISL) & 60853 & 0.0307 & 0.0000 & $\mathrm{n} / \mathrm{a}$ & $\mathrm{n} / \mathrm{a}$ & $\mathrm{n} / \mathrm{a}$ & $n / a$ & & \\
\hline 3 & ISL Reset Ring, butt 1-3 & Part (hsg) / Part (ISL) & 60853 & 0.0281 & 0.0000 & $\mathrm{n} / \mathrm{a}$ & $\mathrm{n} / \mathrm{a}$ & $\mathrm{n} / \mathrm{a}$ & $\mathrm{n} / \mathrm{a}$ & & \\
\hline 3 & ISL Reset Ring, butt 1-4 & Part (hsg) / Part (ISL) & 60853 & 0.0286 & 0.0000 & $\mathrm{n} / \mathrm{a}$ & $\mathrm{n} / \mathrm{a}$ & $\mathrm{n} / \mathrm{a}$ & $\mathrm{n} / \mathrm{a}$ & & \\
\hline 3 & ISL Reset Ring, butt 2-1 & Part (hsg) / Part (ISL) & 60853 & 0.0286 & 0.0000 & $\mathrm{n} / \mathrm{a}$ & $\mathrm{n} / \mathrm{a}$ & $\mathrm{n} / \mathrm{a}$ & $\mathrm{n} / \mathrm{a}$ & & \\
\hline 3 & ISL Reset Ring, butt $2-2$ & Part (hsg) / Part (ISL) & 60853 & 0.0283 & 0.0000 & $\mathrm{n} / \mathrm{a}$ & $\mathrm{n} / \mathrm{a}$ & $\mathrm{n} / \mathrm{a}$ & $\mathrm{n} / \mathrm{a}$ & & \\
\hline 3 & ISL Reset Ring, butt 2-3 & Part (hsg) / Part (ISL) & 60853 & 0.0302 & 0.0000 & $\mathrm{n} / \mathrm{a}$ & $\mathrm{n} / \mathrm{a}$ & $n / a$ & $\mathrm{n} / \mathrm{a}$ & 0.0284 & \\
\hline 3 & ISL Reset Ring, butt 2-4 & Part (hsg) / Part (ISL) & 60853 & 0.0289 & 0.0000 & $\mathrm{n} / \mathrm{a}$ & $\mathrm{n} / \mathrm{a}$ & $\mathrm{n} / \mathrm{a}$ & $\mathrm{n} / \mathrm{a}$ & & \\
\hline 3 & LA 1 & Part (hsg) / SIM (LA) & 60853 & 0.0305 & 0.0000 & $\mathrm{n} / \mathrm{a}$ & $\mathrm{n} / \mathrm{a}$ & $\mathrm{n} / \mathrm{a}$ & $\mathrm{n} / \mathrm{a}$ & & \\
\hline 3 & LA 2 & Part (hsg) / SIM (LA) & 60853 & 0.0267 & 0.0050 & $\mathrm{n} / \mathrm{a}$ & $\mathrm{n} / \mathrm{a}$ & $\mathrm{n} / \mathrm{a}$ & $\mathrm{n} / \mathrm{a}$ & & \\
\hline 3 & LA 3 & Part (hsg) / SIM (LA) & 60853 & 0.0277 & 0.0030 & $\mathrm{n} / \mathrm{a}$ & $\mathrm{n} / \mathrm{a}$ & $\mathrm{n} / \mathrm{a}$ & $\mathrm{n} / \mathrm{a}$ & & \\
\hline 3 & LA 4 & Part (hsg) / SIM (LA) & 60853 & 0.0248 & 0.0060 & 0.0040 & $\mathrm{n} / \mathrm{a}$ & $\mathrm{n} / \mathrm{a}$ & $\mathrm{n} / \mathrm{a}$ & & \\
\hline 4 & ISL Reset Ring, fillet 1-1 & art (VAR ring) / Part (ISL) & 60853 & $\mathrm{n} / \mathrm{a}$ & $\mathrm{n} / \mathrm{a}$ & $\mathrm{n} / \mathrm{a}$ & 0.0113 & fully fused & $\mathrm{n} / \mathrm{a}$ & & \\
\hline 4 & ISL Reset Ring, fillet 1-2 & Part (VAR ring) / Part (ISL) & 60853 & $\mathrm{n} / \mathrm{a}$ & $\mathrm{n} / \mathrm{a}$ & $\mathrm{n} / \mathrm{a}$ & 0.0119 & fully fused & $\mathrm{n} / \mathrm{a}$ & & \\
\hline 4 & ISL Reset Ring, fillet 2-2 & Part (VAR ring) / Part (ISL) & 60853 & $\mathrm{n} / \mathrm{a}$ & $\mathrm{n} / \mathrm{a}$ & $\mathrm{n} / \mathrm{a}$ & 0.0119 & fully fused & $\mathrm{n} / \mathrm{a}$ & & \\
\hline 4 & ISL Reset Ring, fillet 2-3 & Part (VAR ring) / Part (ISL) & 60853 & $\mathrm{n} / \mathrm{a}$ & $\mathrm{n} / \mathrm{a}$ & $\mathrm{n} / \mathrm{a}$ & 0.0111 & fully fused & $\mathrm{n} / \mathrm{a}$ & & \\
\hline 4 & ISL Reset Ring, fillet 2-4 & Part (VAR ring) / Part (ISL) & 60853 & $\mathrm{n} / \mathrm{a}$ & $\mathrm{n} / \mathrm{a}$ & $\mathrm{n} / \mathrm{a}$ & 0.0130 & fully fused & $\mathrm{n} / \mathrm{a}$ & & \\
\hline 5 & Gnd Strap & SIM (strap) / SIM (hsg) & 60800 & $\mathrm{n} / \mathrm{a}$ & $\mathrm{n} / \mathrm{a}$ & $\mathrm{n} / \mathrm{a}$ & 0.0103 & 0.028 & 0.0476 & & \\
\hline 5 & Gnd Strap & SIM (strap) / SIM (hsg) & 60800 & $\mathrm{n} / \mathrm{a}$ & $n / a$ & $\mathrm{n} / \mathrm{a}$ & 0.0105 & 0.031 & 0.0480 & .0104 & \\
\hline 6 & 2nd Attach Pins 1-1 & SIM (hsg) / Part (pin) & 60853 & $\mathrm{n} / \mathrm{a}$ & $n / a$ & $\mathrm{n} / \mathrm{a}$ & 0.0148 & fully fused & $\mathrm{n} / \mathrm{a}$ & & \\
\hline 6 & 2nd Attach Pins 1-2 & SIM (hsg) / Part (pin) & 60853 & $\mathrm{n} / \mathrm{a}$ & $\mathrm{n} / \mathrm{a}$ & $\mathrm{n} / \mathrm{a}$ & 0.0123 & fully fused & $\mathrm{n} / \mathrm{a}$ & .0136 & \\
\hline
\end{tabular}


Appendix “B”

WPQR Settings for Validation 
WPS NOMI NAL SETTI NGS FOR WPQR VALI DATION

\begin{tabular}{|c|c|c|c|c|c|c|c|c|c|c|c|c|}
\hline \multirow[b]{2}{*}{ GROUP\# } & \multirow[b]{2}{*}{ WPS\# } & \multirow[b]{2}{*}{ WELD } & & \multirow[b]{2}{*}{ SEAM } & \multirow[b]{2}{*}{ TACK } & \multirow[b]{2}{*}{$\begin{array}{c}\text { NOM. } \\
\%\end{array}$} & \multirow[b]{2}{*}{$\begin{array}{l}\text { NOMINAL } \\
\text { POWER \& } \\
\text { RANGE }\end{array}$} & \multirow[b]{2}{*}{$\begin{array}{l}\text { WELD } \\
\text { SPEED }\end{array}$} & \multirow[b]{2}{*}{$\begin{array}{l}\text { TACK } \\
\text { TIME } \\
\text { (SEC) }\end{array}$} & \multicolumn{3}{|c|}{$\begin{array}{l}\text { ARGON GAS, } \\
\text { Chrome ball, Mat } 605\end{array}$} \\
\hline & & & & & & & & & & $\begin{array}{l}\text { COAX } \\
\text { FLOW }\end{array}$ & $\begin{array}{l}\text { SIDE } 2 \\
\text { FLOW }\end{array}$ & $\begin{array}{l}\text { SIDE } 1 \\
\text { FLOW }\end{array}$ \\
\hline 2 & 1A1900-LBW1C & J 1 & & $x$ & & 48 & $375+20 /-20$ (SINE) & 80 & N/A & 120 & 120 & 120 \\
\hline 2 & 1A1900-LBW2C & $\mathrm{J} 2$ & & $x$ & & 48 & $375+20 /-20$ (SINE) & 80 & N/A & 120 & 120 & 120 \\
\hline $2 \checkmark$ & 1A1099-LBW3C & j3 & & $\mathrm{x}$ & & 48 & $375+20 /-20$ (SINE) & 80 & N/A & 120 & 120 & 120 \\
\hline 2 & 1A1900-LBW4C & J 4, J 5 & J4, J5, USE SAME SCHEDULE & $\mathrm{x}$ & & 48 & $375+20 /-20$ (SINE) & 80 & N/A & 120 & 120 & 120 \\
\hline $2 \checkmark$ & 1A1099-LBW6C & J6, J7, J8 & J $6, \jmath 7, \jmath 8$, USE SAME SCHEDULE & $x$ & & 48 & $375+20 /-20$ (SINE) & 80 & $\mathrm{~N} / \mathrm{A}$ & 120 & 120 & 120 \\
\hline $6 \checkmark$ & 1A1099-LBW9C & 2nd ATTACHMENT PINS & & & $\mathrm{x}$ & 25 & $375+20 /-20$ (SINE) & 80 & 0.040 & 120 & 120 & 120 \\
\hline $1 \checkmark$ & 1A1099-LBW10C & TRAJ ECTORY STRONG LINK (TSL) & & $x$ & & 45 & $345+20 /-20$ (SINE) & 80 & N/A & 120 & 120 & 120 \\
\hline 3 & 1A1099-LBW11C & INTENT STRONG LINK (ISL) & & $x$ & & 48 & $375+20 /-20$ (SINE) & 80 & N/A & 120 & 120 & 120 \\
\hline $4 \checkmark$ & 1A1099-LBW12C & RESET RING, ISL (FILLET) & & $x$ & & 48 & $375+20 /-20$ (SINE) & 70 & N/A & 120 & 120 & 120 \\
\hline $3 \checkmark$ & 1A1099-LBW13C & RESET RING, ISL (BUTT) & & $x$ & & 48 & $375+20 /-20$ (SINE) & 80 & N/A & 120 & 120 & 120 \\
\hline 4 & 1A1900-LBW14C & RESET RING, TSL (FILLET) & & $x$ & & 48 & $375+20 /-20$ (SINE) & 70 & $\mathrm{~N} / \mathrm{A}$ & 120 & 120 & 120 \\
\hline 3 & 1A1900-LBW15C & RESET RING, TSL (BUTT) & & $x$ & & 48 & $375+20 /-20$ (SINE) & 80 & N/A & 120 & 120 & 120 \\
\hline $5 \checkmark$ & 1A1900-LBW16C & CDU GROUND STRAP & & & & & & 80 & 0.040 & 120 & 120 & 120 \\
\hline 5 & 1A1900-LBW16C & FLATNESS COVER ISL & $\begin{array}{c}\text { CDU GND. STRAP, ISL/TSL FLAT COVERS } \\
\text { USE THE SAME SCHEDULE }\end{array}$ & & $x$ & 25 & $420+25 /-0(\mathrm{CW})$ & 80 & N/A & 120 & 120 & 120 \\
\hline 5 & 1A1900-LBW16C & FLATNESS COVER TSL & & & & & & 80 & $\mathrm{~N} / \mathrm{A}$ & 120 & 120 & 120 \\
\hline 3 & 1A1900-LBW17C & REGION 2 COVER & & $x$ & & 48 & $375+25 /-10$ (SINE) & 80 & N/A & 120 & 120 & 120 \\
\hline 3 & 1A1900-LBW18C & FWD COVER & & $x$ & & 48 & $375+25 /-10$ (SINE) & 80 & N/A & 120 & 120 & 120 \\
\hline 3 & 1A1900-LBW18CT & FWD COVER (TILT) & & $x$ & & 48 & $375+25 /-10$ (SINE) & 80 & N/A & 120 & 120 & 120 \\
\hline 3 & 1A1900-LBW19C & AFT COVER & & $\mathrm{x}$ & & 48 & $375+25 /-10$ (SINE) & 80 & N/A & 120 & 120 & 120 \\
\hline 3 & 1A1900-LBW21C & LAUNCH ACCELEROMETER (LA) & & $x$ & & 48 & $375+25 /-10$ (SINE) & 80 & $\mathrm{~N} / \mathrm{A}$ & 120 & 120 & 120 \\
\hline 3 & 1A1900-LBW22C & PURGE TUBE (PT) & & $x$ & & 48 & $375+25 /-10$ (SINE) & 80 & $\mathrm{~N} / \mathrm{A}$ & 120 & 120 & 120 \\
\hline $\mathrm{n} / \mathrm{a}$ & 1A1099-LBW26C & MANUAL TACK WELDING & $\begin{array}{l}\text { CDU GND. STUD, MANUAL TACK } \\
\text { USE THE SAME SCHEDULE }\end{array}$ & & $x$ & 25 & $420+25 /-0(\mathrm{CW})$ & 80 & 0.020 & 120 & 120 & 120 \\
\hline $\mathrm{n} / \mathrm{a}$ & 1A1099-LBW28C & TSL ALIGNMENT PASS & & $\mathrm{N} / \mathrm{A}$ & $\mathrm{N} / \mathrm{A}$ & $\mathrm{N} / \mathrm{A}$ & $375+25 /-10$ (SINE) & 80 & N/A & N/A & N/A & N/A \\
\hline $\mathrm{n} / \mathrm{a}$ & 1A1099-LBW30C & "SNAP-PLATE" FUNCTIONAL & & $\mathrm{x}$ & & 48 & $375+25 /-10$ (SINE) & 80 & $\mathrm{~N} / \mathrm{A}$ & 120 & 120 & 120 \\
\hline $\begin{array}{l}8 \\
\checkmark\end{array}$ & $\begin{array}{l}\text { 1A1078-LBW1C } \\
\text { indicates parts welc }\end{array}$ & $\begin{array}{c}\text { CDU GROUND STUD* } \\
\text { *not qualified }^{\text {not }}\end{array}$ & SAME AS 1A1099-LBW26C & * & * & * & $*$ & $*$ & $*$ & $*$ & * & * \\
\hline
\end{tabular}


Appendix "C"

Weld Metallography 


\section{Secondary Attachment Pins and Ground Strap/ Flatness Covers}

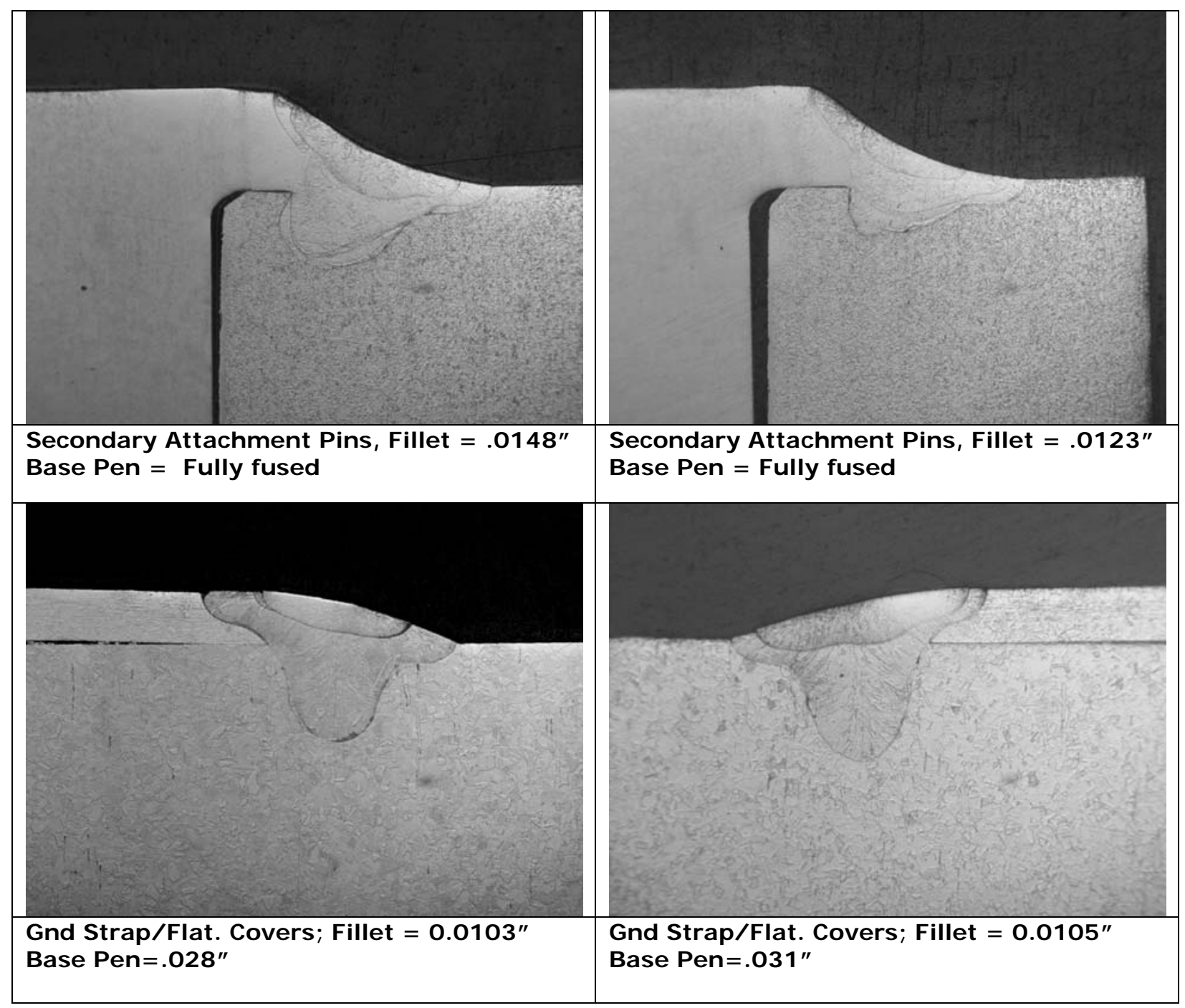


J 3 Connector

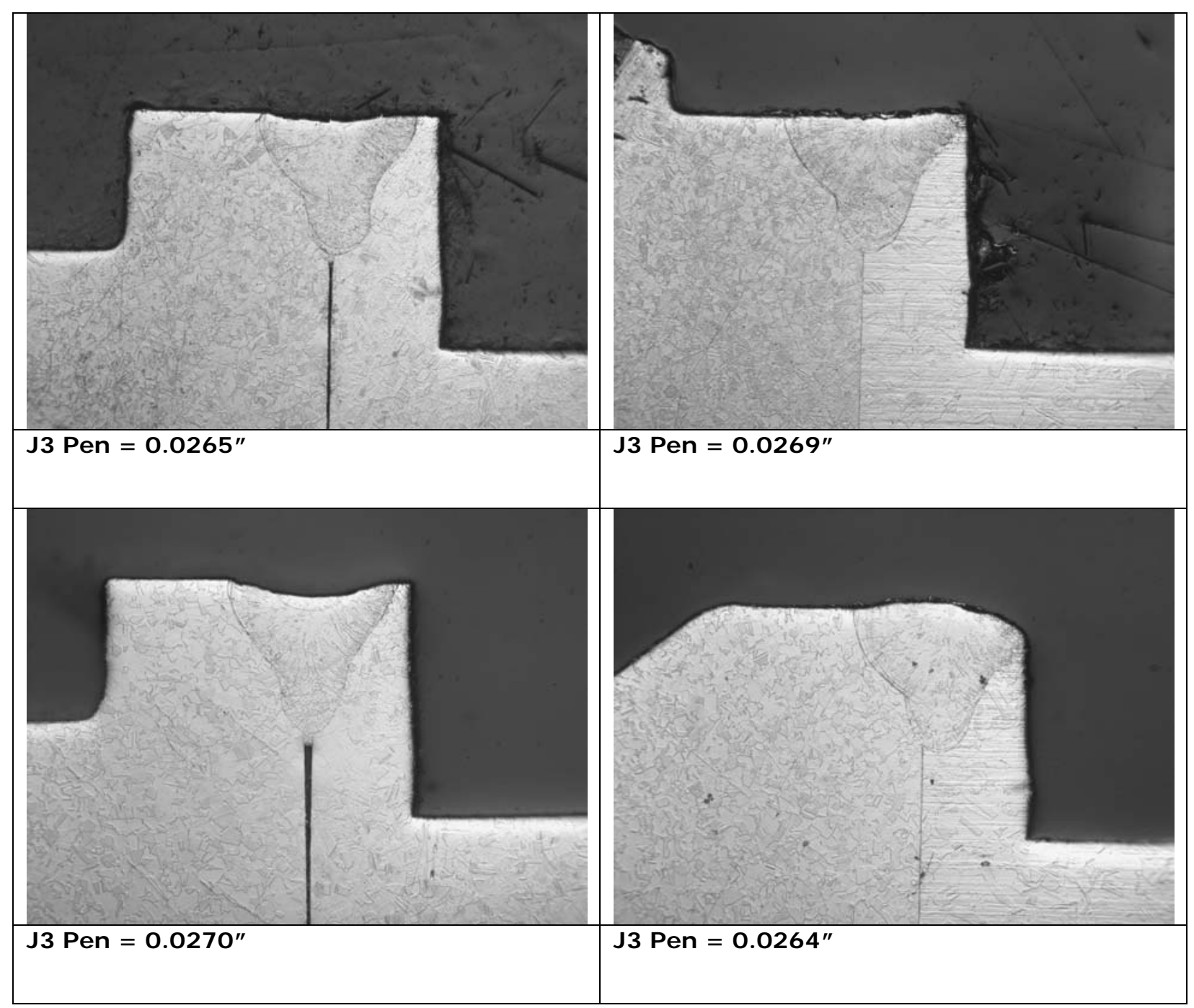




\section{J 7 Connector}

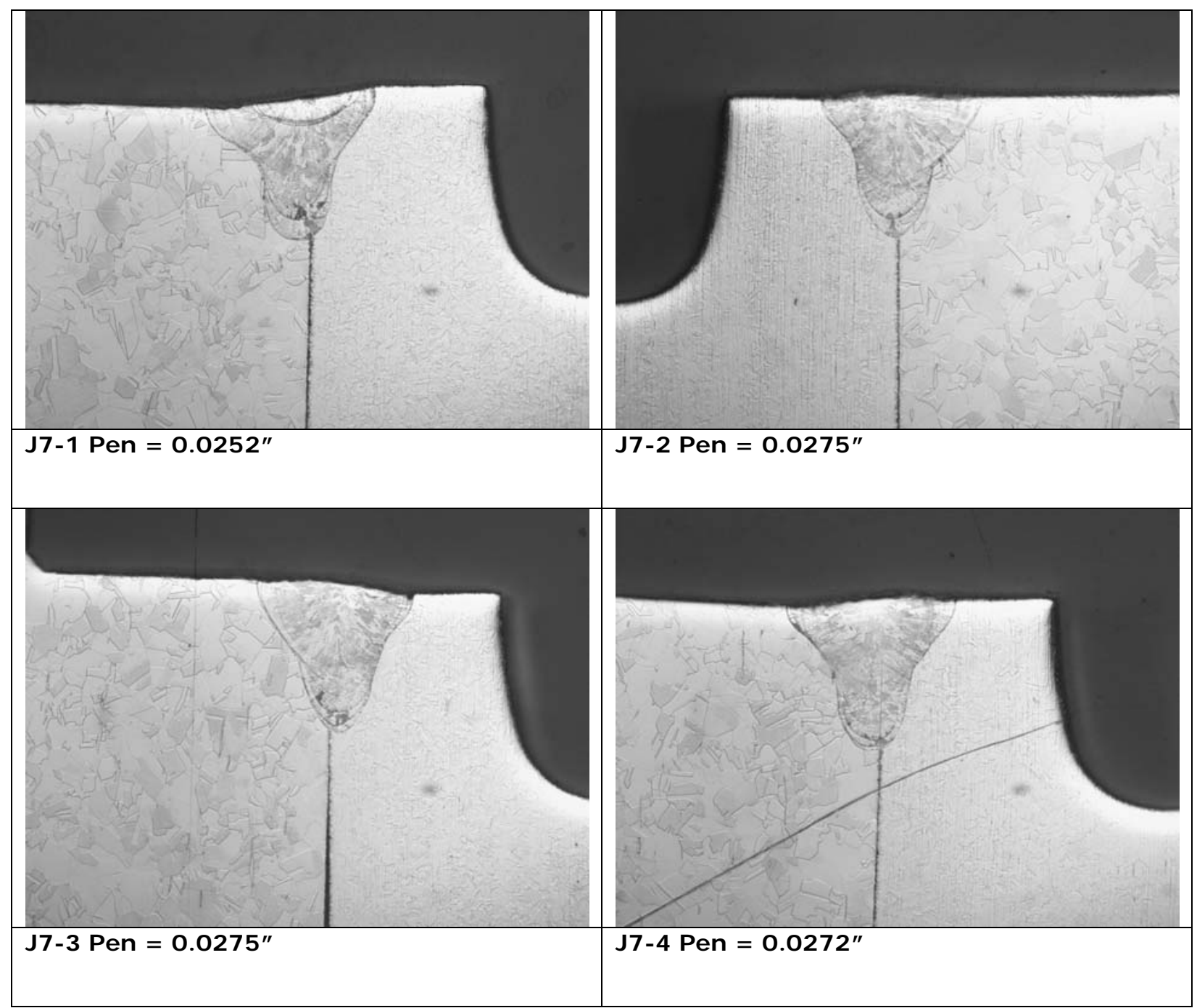




\section{J 8 Connector}

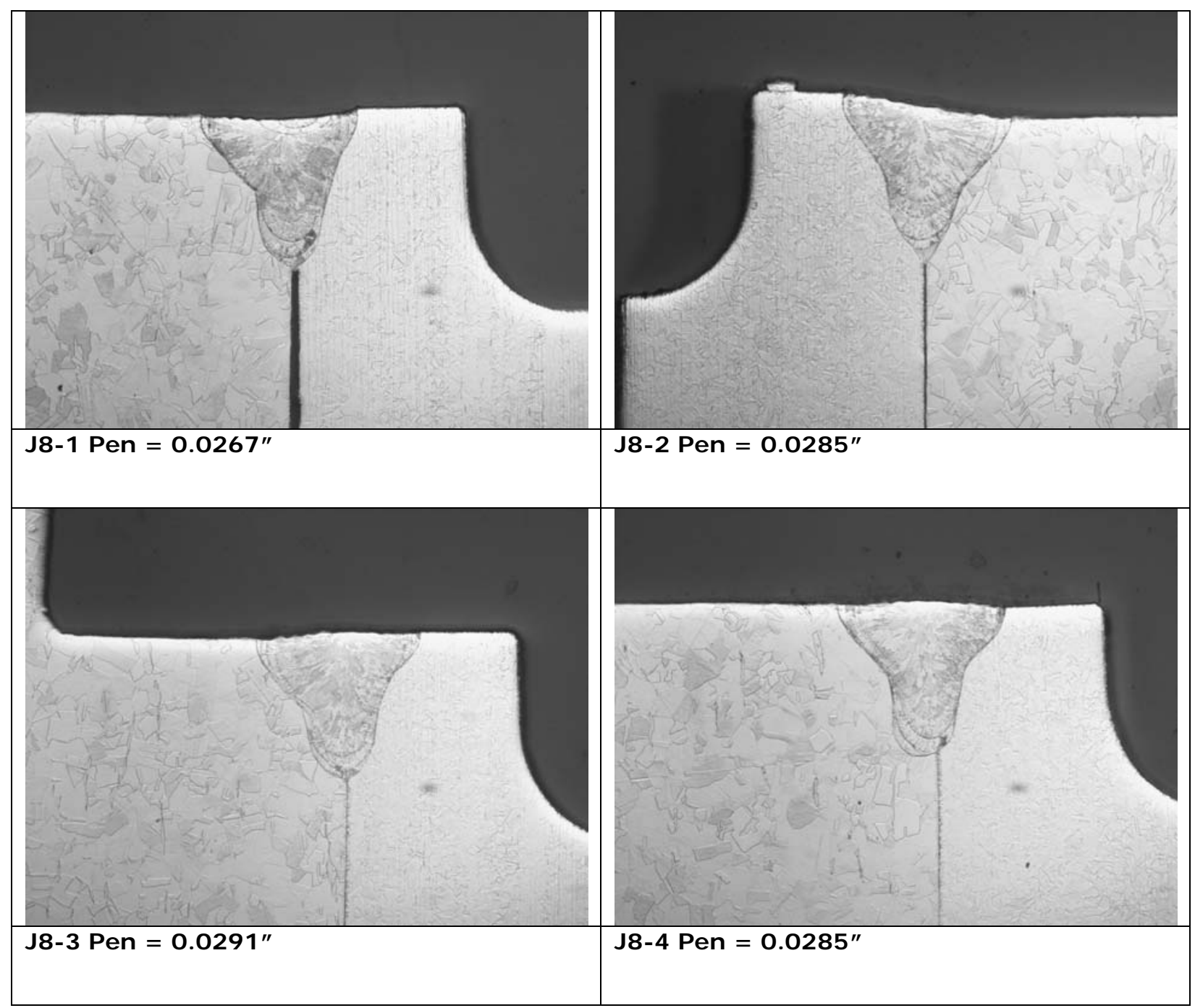




\section{Launch Accelerometer (LA)}

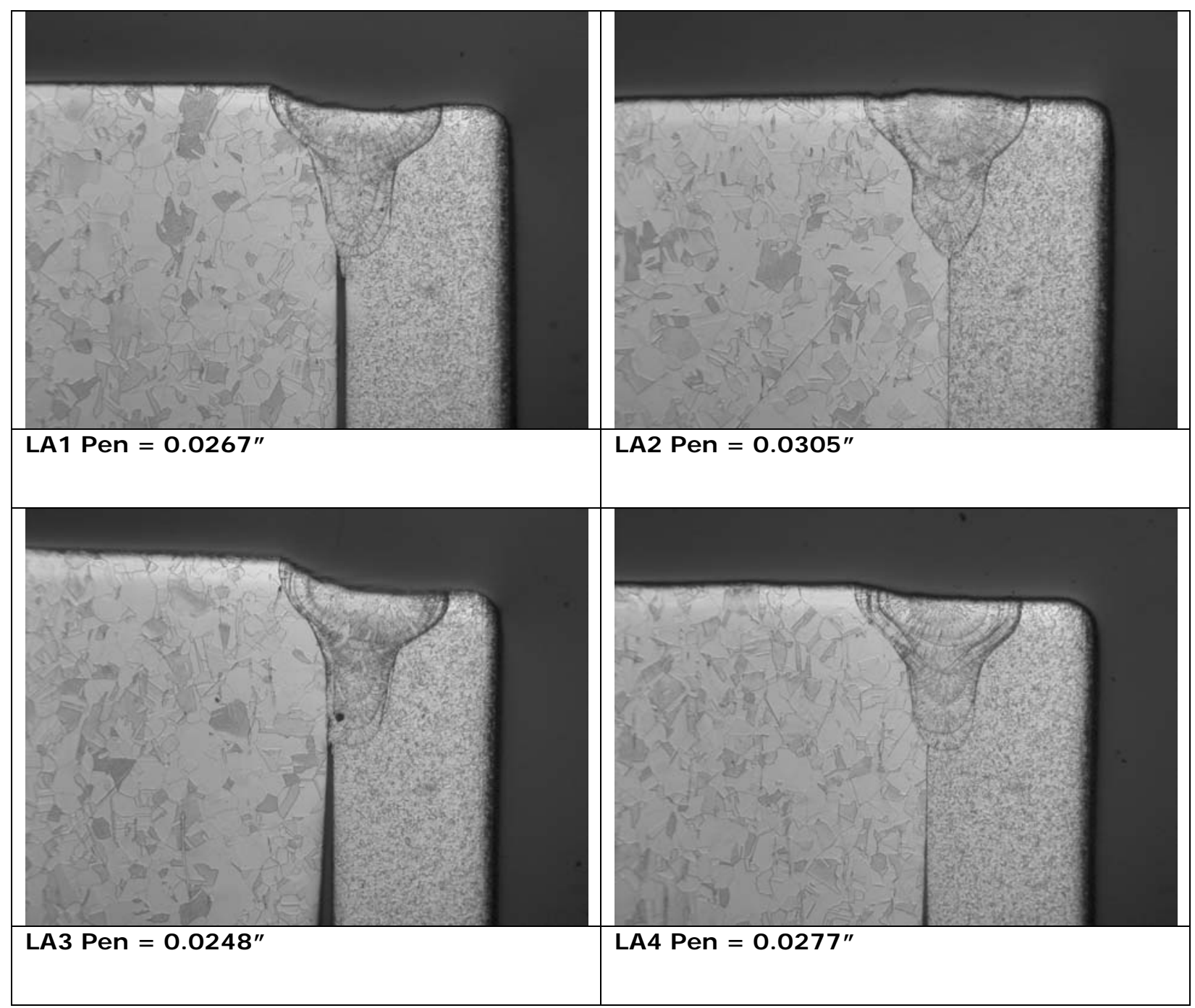




\section{SL Reset Ring \# 1}

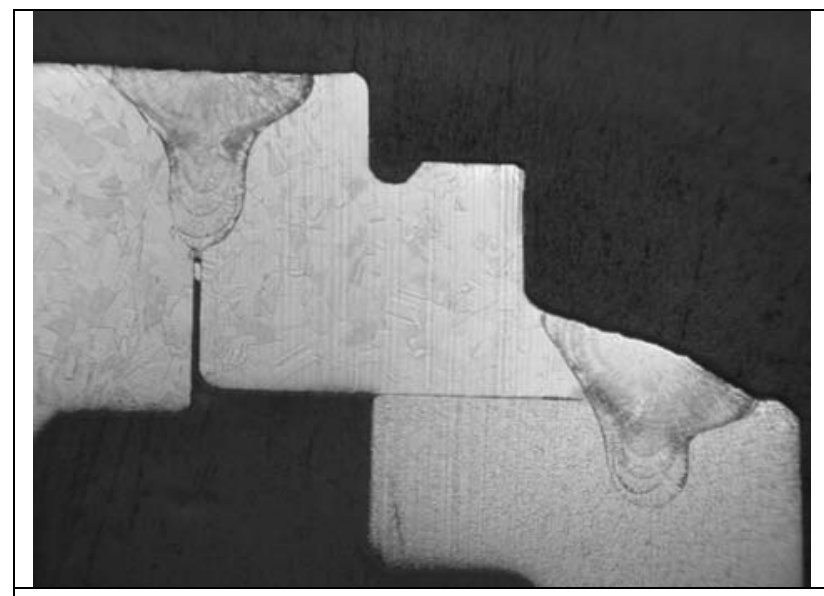

RRing1-1 Pen=0.0278" Fillet $=0.0113 "$ Base is fully fused. Fillets were rewelded to test rew orkability.

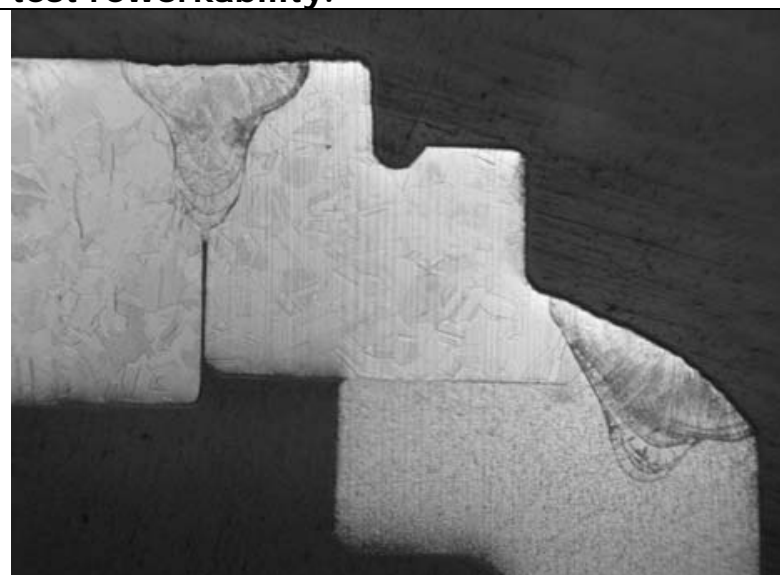

RRing1-1 Pen=0.0281" Fillet $=0.0116 "$ Base is fully fused. Fillets were rewelded to test rew orkability.

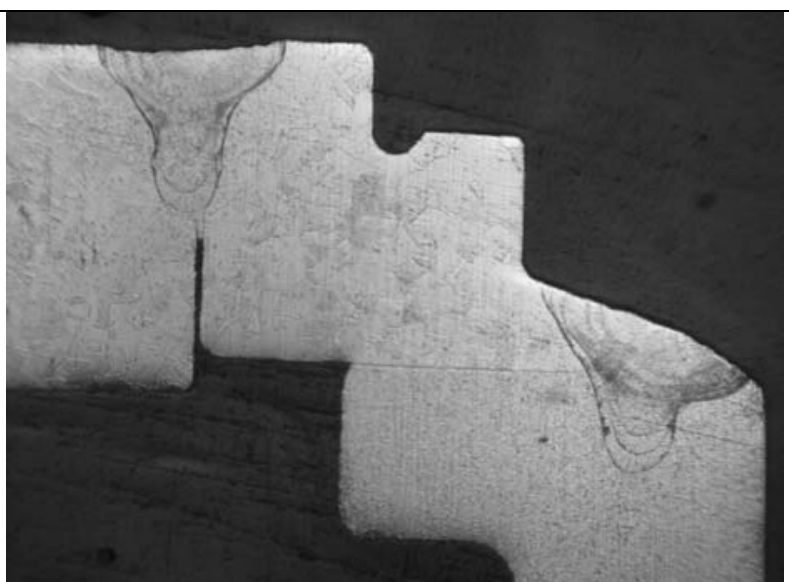

RRing1-2 Pen $=0.0307$ " Fillet $=0.0119$ " Base is fully fused. Fillets were rewelded to test reworkability.

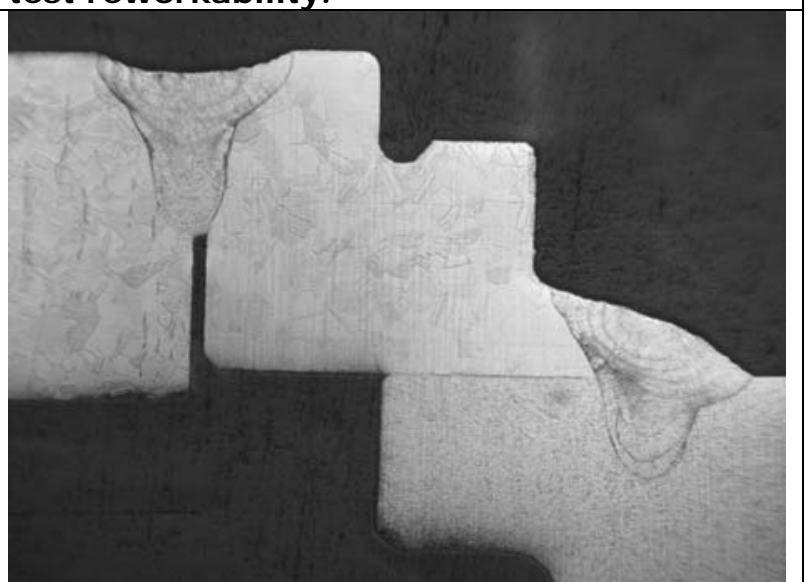

RRing1-1 Pen $=0.0286$ " Fillet $=0.0132$ " Base is fully fused. Fillets were rewelded to test reworkability. 
ISL Reset Ring \# 2

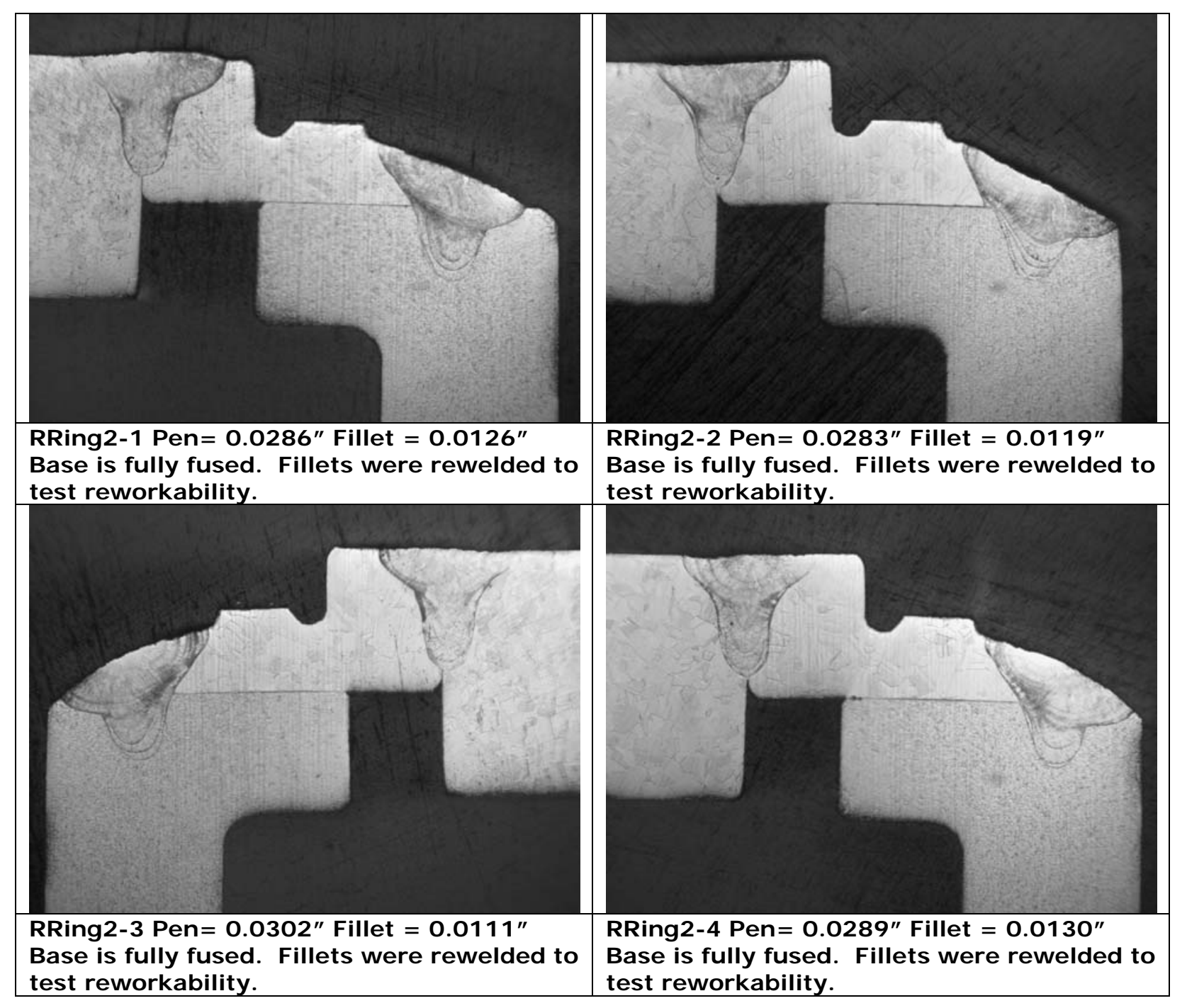


TSL
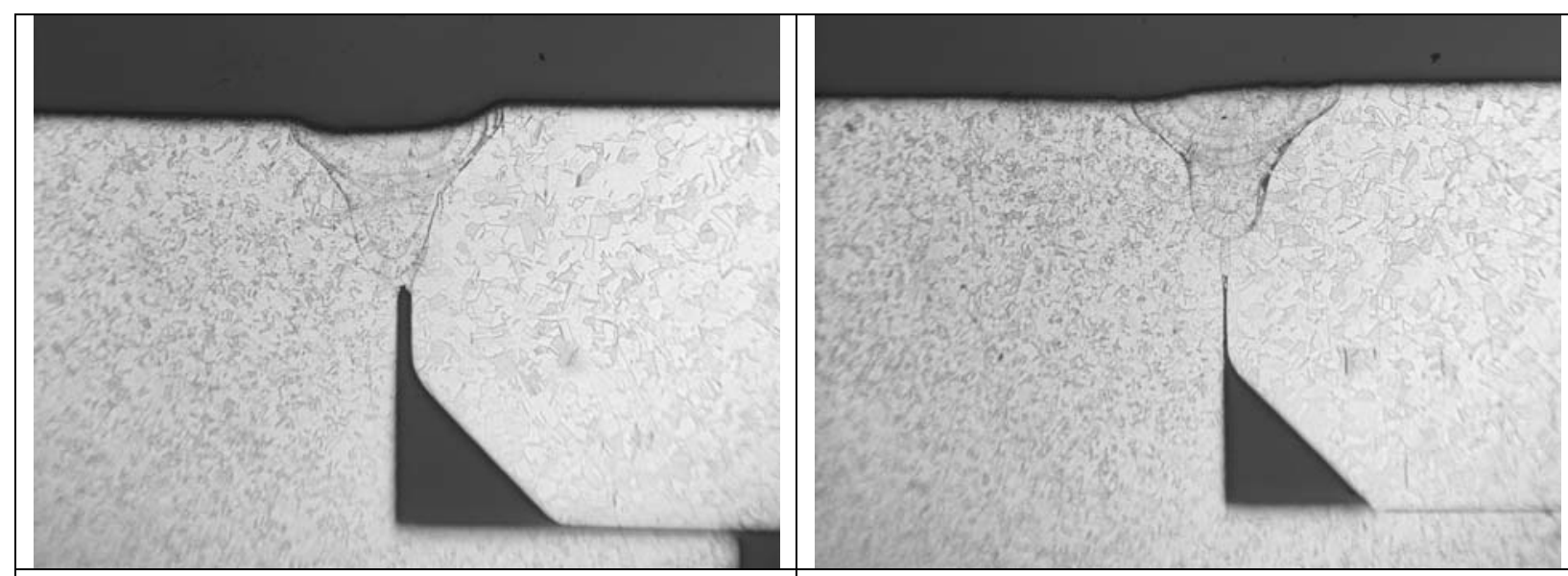

TSL1, 1A Pen $=0.0242 "$

TSL1, 2A Pen $=0.0224 "$

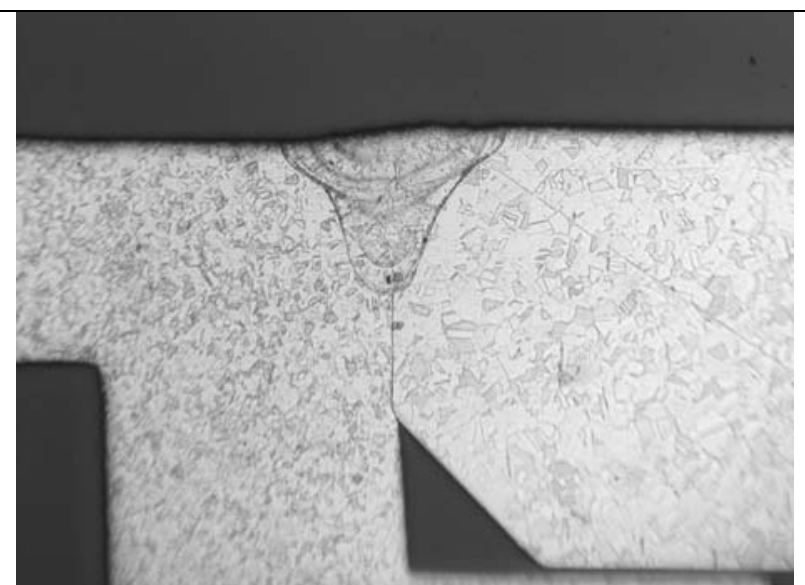

TSL1, 1B Pen $=0.0198 "$

TSL1, 1C Pen $=0.0222 "$

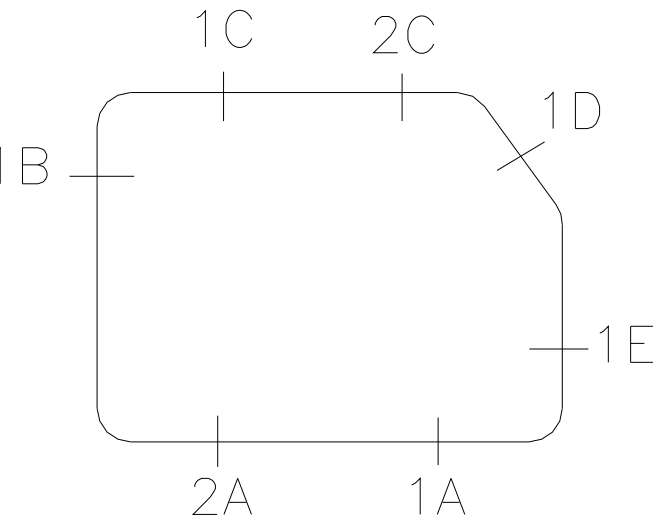



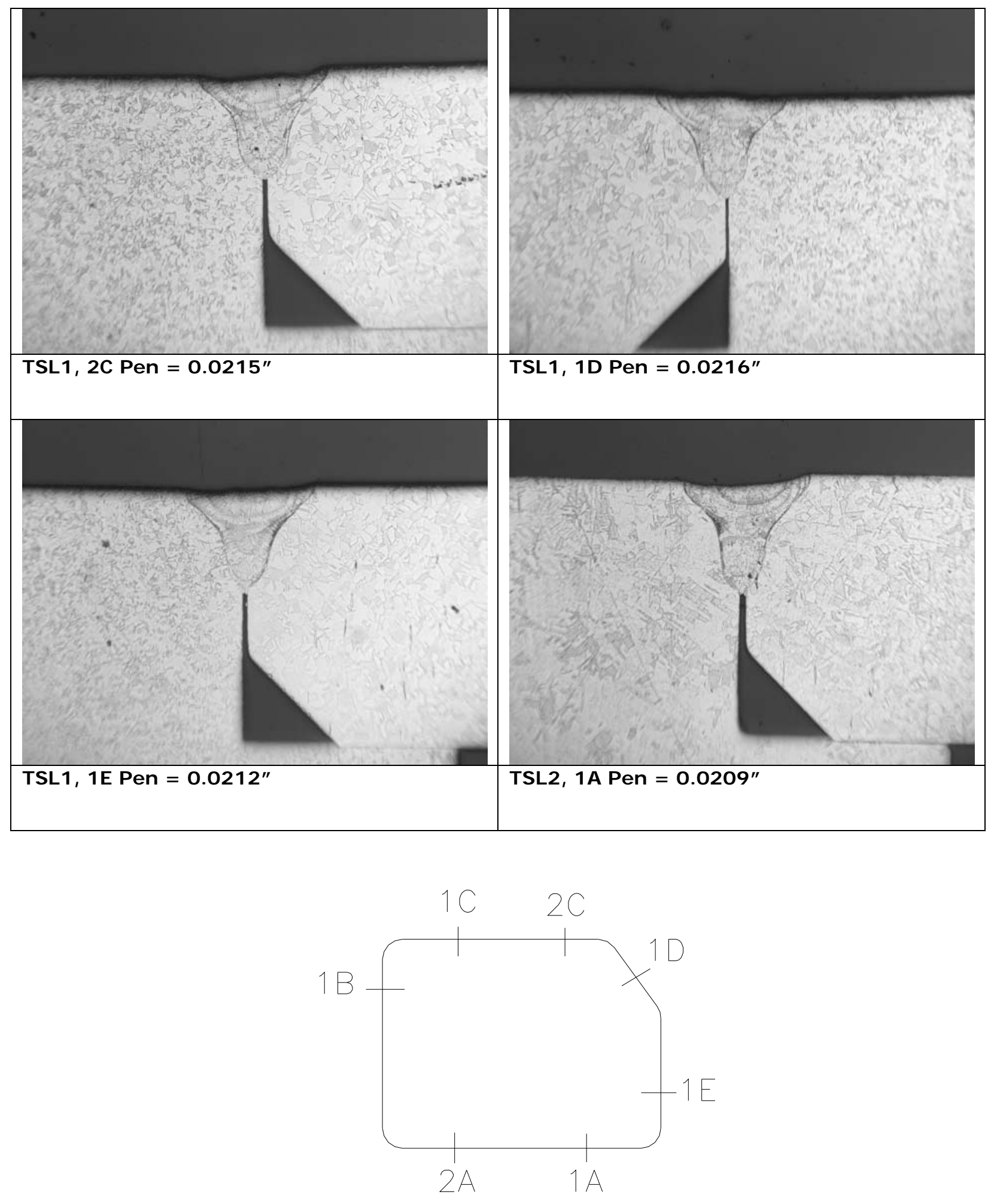

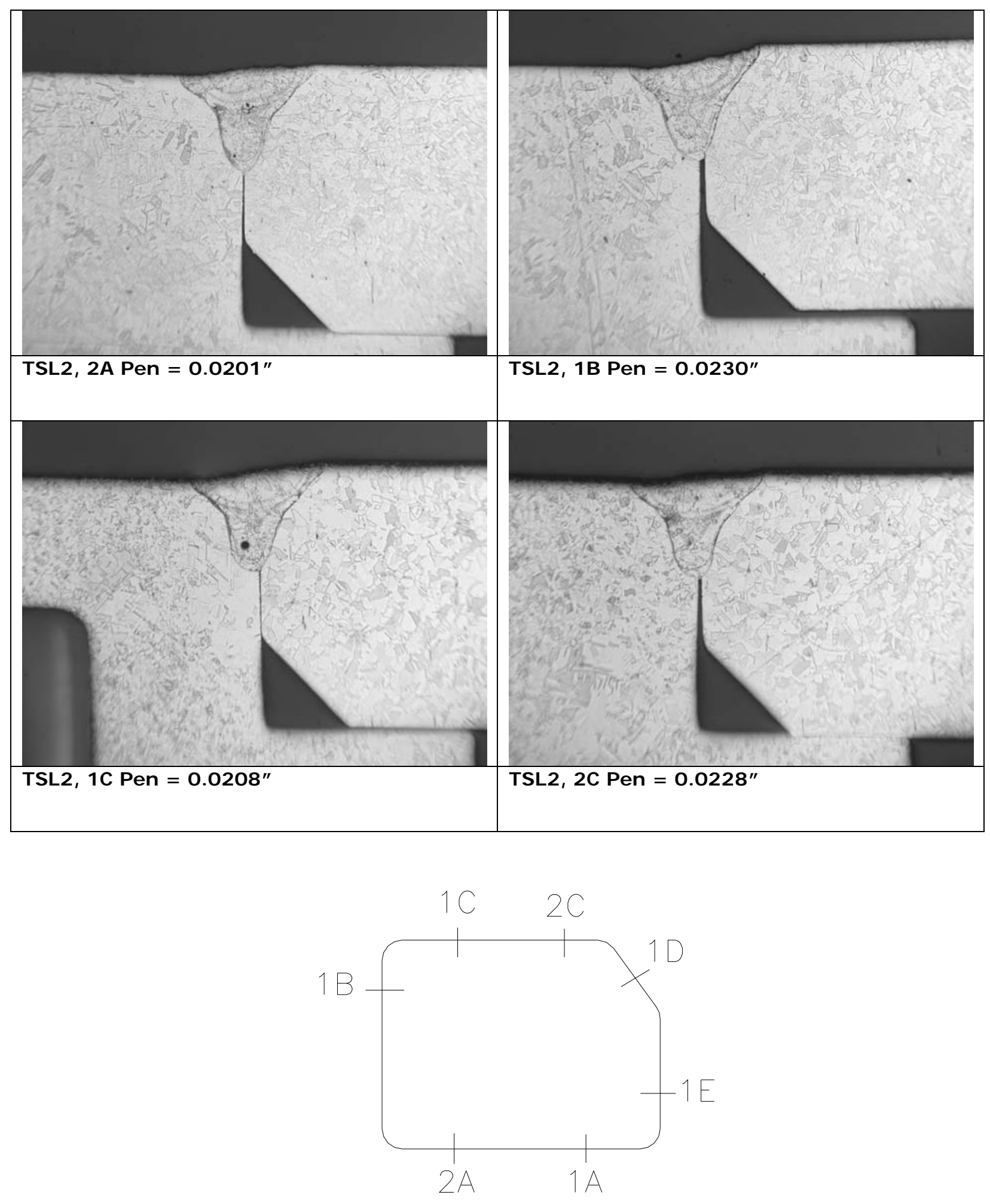

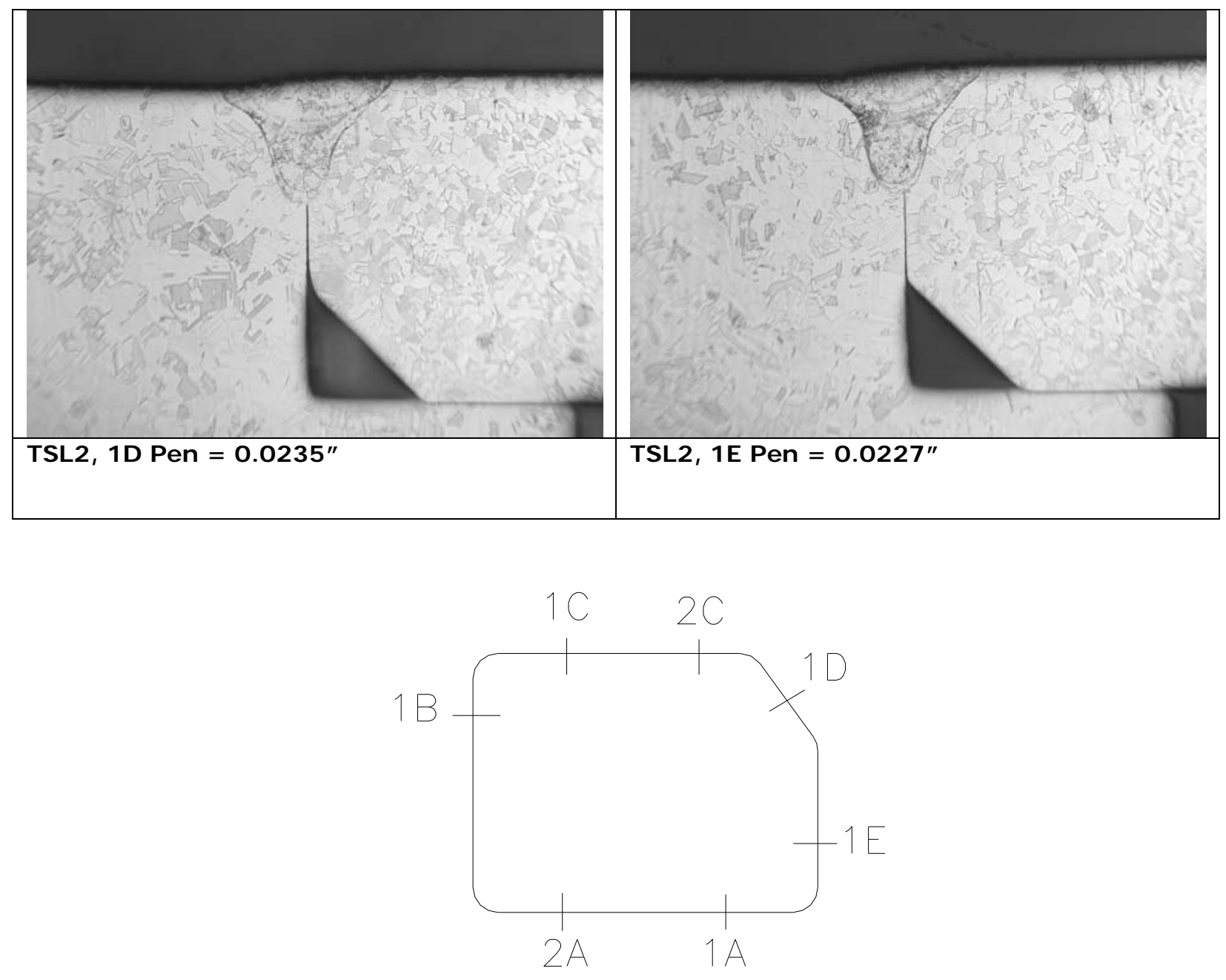